InI)ret

3.2020

Jordi Nieva-Fenoll

Universitat de Barcelona

\section{Carga de la prueba y estándares de prueba: dos reminiscencias del pasado}

\section{Sumario}

La carga de la prueba y los estándares de prueba son dos instituciones que provienen del antiguo sistema de valoración legal o tasada de la prueba, en el que tenían todo su sentido. Sin embargo, en el sistema de valoración libre, la institución de la carga de la prueba deja de tener cualquier utilidad, y los estándares de prueba se convierten en simples remedos de las antiguas categorías "probatio plena" y "probatio semiplena" que resultan imposibles de objetivar. En el presente artículo se detallan y justifican extensamente las anteriores conclusiones.

\begin{abstract}
The burden of proof and the standards of proof are two institutions that come from the old system of legal proof, in which they made sense. However, if evidence is free evaluated, the burden of proof is no longer useful and the standards of proof become mere imitations of the old categories "probatio plena" and "semiplena probatio" that are impossible to objectify. In this paper these conclusions are duly detailed and extensively justified.
\end{abstract}

Title: Burden of the Proof and Standards of Proof: Two Rests from the Past

Palabras clave: Carga objetiva, Carga subjetiva, Valoración, Prueba legal Keywords: Burden of persuation, burden of production, Evaluation, Legal proof

DOI: $10.31009 /$ InDret.2020.i3.13 


\section{InIDret}

3.2020

Recepción

19/05/2020

Aceptación

20/07/2020
Îndice

\section{-}

Este trabajo se publica con una licencia Creative Commons Reconocimiento-No Comercial 4.0 Internacional @) (1) @ (9) 


\section{Introducción}

El destino de la prueba presentada en un proceso es valorarla racionalmente, es decir, de veras. No se pueden establecer atajos en este camino, aunque con frecuencia esa actividad de valoración sea tan sumamente difícil que, ciertamente, el jurista desearía disponer de algún tipo de herramienta, casi una piedra filosofal, para conocer cuál es la realidad de los hechos. Porque valorar la prueba consiste justamente en eso: en averiguar la realidad ${ }^{1}$.

La dificultad no es nueva. Históricamente se intentaron ofrecer ayudas a los jueces. Las arcaicas normas de prueba legal del código de Hammurabi ${ }^{2}$ dan buena prueba de ello, y todos los ejemplos establecidos en el Corpus Iuris Civilis $^{3}$-luego reproducidos en leyes medievales ${ }^{4}$ - van por esa misma línea. Pero justamente en la Edad Media surgen dos institutos, no tanto llamados a hacer la vida más fácil a los jueces en este sentido, como más bien a poner fronteras a su labor ${ }^{5}$, en la línea iniciada por el secundum allegata et probata ${ }^{6}$ que configuraron AzzonE y

\footnotetext{
*Autor de contacto: Jordi Nieva-Fenoll, jordinieva@ub.edu.

${ }^{1}$ Lo explico in extenso en NiEva FenolL, La valoración de la prueba, Madrid 2010.

${ }^{2}$ Vid. las traducciones originales, que he alterado en parte, en LARA PEINADO, Federico, Código de Hammurabi, Madrid 1997, pág. 6. y sigs:
}

§7 Si alguien manifiesta haber adquirido o recibido en depósito plata, oro, esclavo o esclava, buey, oveja o asno o cualquiera otra cosa, sin testigos ni contrato, será considerado reo de robo y condenado a muerte. $\$ 10$ Si el comprador no ha presentado al vendedor que le vendió la cosa, ni a los testigos en cuya presencia se efectuó la compra, y el dueño de la cosa perdida presenta testigos que atestigüen (la preexistencia de) la cosa (y el dominio) de dicho propietario, el comprador fue el ladrón: será castigado con la muerte. El propietario de la cosa perdida recobrará su propiedad.

§11 Si el propietario de la cosa perdida no presenta testigos que presten testimonio sobre dicho objeto, es un farsante, y puesto que denunció falsamente, será castigado con la muerte.

§13 Si los testigos del anterior denunciante no estuviesen localizables, los jueces le señalarán un plazo de seis meses. Y si al término del mismo no presenta sus testigos, será considerado un farsante y sufrirá en su totalidad la pena de este proceso.

§150: Si el marido donó a su esposa campo, huerta o casa, y le escribió un documento al respecto, después de la muerte del marido sus hijos no podrán reclamarle nada; la madre dejará en herencia esos bienes al hijo que prefiera, pero no a un extraño.

§182 Si un padre tiene una hija que sea sacerdotisa de Marduk de Babilonia y no la dotó escribiéndole un documento sellado, a la muerte del padre le corresponderá un tercio de la herencia, que podrá dejar en sucesión a quien prefiera.

§183: Si un padre tiene una hija concubina, y le da dote, le concede marido y le otorga documento sellado al respecto, a la muerte de su padre no heredará ningún bien.

${ }^{3}$ Por ejemplo, Codex, Libro IV, título XX, no 9, §1: Simili modo sauximus, ut unius testimonium nemo iudicium in quacunque causa facile patiatur admitti. Et nunc manifeste sancimus, ut unius omnino testis responsio non audiatur, etiamsi praeclarae curiae honore praefulgeat.

${ }^{4}$ Fuero Juzgo, Lib. II, tít. II, VI. En los pleytos que el iues oye, cada una de las partes debe dar sus pesquisas é sus pruevas, y el iuez debe catar qual prueva meior. E si por las pruevas non pudiere saber la verdad, estonze debe mandar el iues á aquel de quien se querellavan, que se salve por su sacramiento, que aquella cosa quel demandan, non la ovo, nin la a, ni sabe ende nada, ni lo cree, ni que non fizo aquello quel dizen. E pues que iurar aquel quel demandó tuerto, peche V. sueldos. Vid. también Partida III, tít. XVI, Leyes 29 y 32 .

${ }^{5}$ Lo explico en Nieva FenolL, “La actuación de oficio del juez nacional europeo”, Diario La Ley, n. 9000, 146-2017, traducido al italiano en NIEVA FENOLL, “I poteri d'ufficio del giudice nazionale europeo”, Rivista Trimestrale di Diritto e Procedura Civile, 4, 2019, págs. 1223 y sigs.

${ }^{6}$ Vid. NÖRR, K. W., Zur Stellung des Richters im gelehrten Prozeß der Frühzeit: Iudex secundum allegata non secundum conscientiam iudicat, München 1967. 
ACCURSIO $^{7}$. Así surgieron, como veremos seguidamente, tanto el onus probandi como las medidas de prueba, el antecedente de los actuales estándares de prueba y del Beweismaß alemán.

Sin embargo, sea cual fuere el origen de las instituciones, estas van mutando con el tiempo, y finalmente pueden acabar transformándose en algo irreconocible para sus creadores. Y es justamente esto lo que ha sucedido con las dos instituciones en cuestión. Probablemente si a un jurista medieval le habláramos de algo "más allá de toda duda razonable”, o bien de "carga objetiva de la prueba", y le dijéramos que, junto con la subjetiva, es algo a utilizar solamente al final del proceso cuando aparece una situación de ausencia de prueba -Beweislosigkeit ${ }^{8}-$, no entendería absolutamente nada.

A continuación iré explicando poco a poco todo lo anterior acompañando la exposición de un relato ligero de la historia pero sin ninguna clase de prejuicio histórico. Bien al contrario, se comenzará la explicación concretando las definiciones que de ambos conceptos ofrece ahora mismo la doctrina. Después serán sometidas a la comprobación histórica y práctica, y de los resultados que objetivamente se obtengan se extraerán conclusiones precisas.

\section{Concepto y variedades de la carga de la prueba.}

La carga de la prueba no tiene una definición unívoca en absoluto. En realidad, se trata de una expresión que condensa diferentes ideas que no tienen tanto que ver entre sí como se piensa. De hecho, vamos a ver a continuación que realmente tienen bastante poco que ver.

En la Edad Media se construyó la noción de onus probandi recogiendo restos del proceso romano ${ }^{9}$ sacados del contexto origina ${ }^{10}$. Pero sea como fuere, se asentó la idea de que cada parte tenía que aportar prueba de lo que decía. Dicho de otro modo, que cada litigante poseía la

\footnotetext{
${ }^{7}$ Azzone (o Azo o AzÓN), Brocardica (aurea). sive generalia iuris, Basilea 1567, rúbrica XX, pág. 237: Iudex debet ex conscientia iudicare, \& econtrà.] Secundum allegata iudicare debet. Cum quaeritur, an iudex debeat iudicare secundum conscientiam suam, in causa civili vel criminali, distingue: utrum notum sit ei tamquam iudici, id est, ratione officii sui: an ut privato. In primo casu fertur sentencia secundum conscientiam suam; quae etiam potest dici allegatio. ut ff. de ser. 1.2.\&ff. Si fer. vend.1 surreptionem. \& de minor. 25. anno.l.minor. Quid miri? nonne sert sententiam, secundum testificationes \& confessiones, quas novit ut iudex? \& et ita potest intellegi hoc generale. Si vero novit ut privatus, non debet ferre sententiam secundum conscientiam suam, sed secundum allegata. \& ita intelligitur contraria Rubrica. Accursius, e.a., Corporis Iustinianaei Digestum Vetus, seu Pandectarum, Vol. 6, Lyon 1604, pág. 17: "Iudex debet ferre sententiam, secundum allegata et probata, non secundum conscientiam."

${ }^{8}$ Vid. Rosenberg, Die Beweislast, Berlin 1923, págs. 35 y 55. LeIPold, Dieter, Comentario al §286 ZPO, en: “Stein/JonAS, Kommentar zur ZPO, Tübingen 1997”,pág. 525. RosEnBERg / SchwAB / GotTwALD, Zivilprozeßrecht, München 2018,pág. 698. MONTERo AROCA, La prueba en el proceso civil, Cizur Menor 2005, pág. 112. Serra Domínguez, Manuel, Comentario al art. 1214, en: “AAVV (dir. Albaladejo), Comentarios al Código Civil y compilaciones forales, Madrid 1991, pág. 55. NieVA Fenoll, "Los sistemas de valoración de la prueba y la carga de la prueba: nociones que precisan revisión”, en La ciencia jurisdiccional: novedad y tradición, Madrid 2016, pág. 271. NieVA FenolL, Derecho procesal II. Proceso civil, Valencia 2019, pág. 201. ESCALER BASCOMPTE, Ramon, La carga de la prueba, Barcelona 2017, pág. 83.

${ }^{9}$ KASER / HACKL, Das römische Zivilprozessrecht, München 1996,pág. 493. PrÜTTING, Hanns, “Carga de la prueba y estándar probatorio: la influencia de Leo Rosenberg y Karl Heinz Schwab para el desarrollo del moderno Derecho probatorio”, Revista Ius et Praxis, 2010, n. 1, pág. 457.

${ }^{10}$ Vid. NÖRR, Knut Wolfgang, Romanisch-kanonisches Prozessrecht, Berlin 2012, págs. 78 y sigs.
} 
carga de probar lo que afirmaba para tener una expectativa de ganar el proceso ${ }^{11}$. Ese fue el onus probandi y ese es, por tanto, el primer concepto de la carga de la prueba: la obligación de cada parte de traer pruebas al proceso en defensa de su posición. Era, además, una obligación muy antigua ${ }^{12}$ y realmente bastante lógica, casi intuitiva. Si se parte de la máxima de la experiencia de que, salvo casos excepcionales, el adversario siempre obra en su propio beneficio y nada hace por su enemigo, la prueba era, en esa antigua concepción, una de sus principales armas para ganar el proceso.

El concepto es coincidente con la primera acepción moderna del descrito onus probandi medieval: la llamada carga subjetiva de la prueba, también denominada carga formal ${ }^{13}$. Supone precisamente eso, que cada parte debe aportar al proceso la prueba de los hechos que le son favorables ${ }^{14}$, tal y como dispone de modo muy sintético, por ejemplo, el art. 196 del Código Procesal Civil peruano de $1993^{15}$. La doctrina incluso trazó un mapa de dichos hechos para orientar a los litigantes, estableciendo que el demandante debe probar los hechos constitutivos de su pretensión, y el demandante los hechos impeditivos, extintivos y excluyentes de dicha pretensión ${ }^{16}$. Sin tanto detalle pero con la misma idea de fondo, se habló en el Common Law de la burden of production en EEUU ${ }^{17} \mathrm{o}$ evidential burden en el Reino Unido ${ }^{18}$, que son simplemente un remedo de la carga subjetiva con su mismo contenido.

Se confirma que se trata, por tanto, de la concepción originaria de la carga de la prueba después de la Edad Media. La doctrina posterior, consciente de lo injusto de la regla entendida de manera estricta, dibujó diferentes formas de suavizarla ${ }^{19}$. Arrancó BENTHAM ${ }^{20}$ con una antigua idea medieval ${ }^{21}$ que rescata en su conocido libro sobre la materia, y que establece que debe tener la carga -siempre subjetiva- de la prueba la parte a la que le resulte más fácil probar un

\footnotetext{
${ }^{11}$ Lo explico en Nieva Fenoll, "La carga de la prueba: una reliquia histórica que debiera ser abolida”, en NieVA / FERRER / GiANNini, Contra la carga de la prueba, Madrid 2019, págs. 25 y sigs.

${ }^{12}$ KASER / HACKL, Das römische Zivilprozessrecht, cit. pág. 118.

${ }^{13}$ Vid. SunDELIN,pág., Die Staats-Anwaltschaft in Deutschland, Anklam 1860,pág. 121.

${ }^{14}$ WeBER, Adolph Dieterich, Ueber die Verbindlichkeit zur Beweisführung im Civilprozeß, Halle 1805, págs. 154 y sigs.

${ }^{15}$ Artículo 196.- Carga de la prueba.- Salvo disposición legal diferente, la carga de probar corresponde a quien afirma hechos que configuran su pretensión, o a quien los contradice alegando nuevos hechos.

${ }^{16}$ LeIPOLD, Dieter, Comentario al §286 ZPO, en: “Stein/JonAS, Kommentar zur ZPO, Tübingen 1997”,pág. 527. Vid. también D’ALESSANDRO, E., “Onere della prova e legge applicabile”, Giurisprudenza italiana, Nov. 2018,pág. 2546.

${ }^{17}$ Redmayne, Mike, “Standards of Proof in Civil Litigation”, Modern Law Review 62, n.2, marzo 1999, pág. 172.

${ }^{18}$ DenNis, The Law of Evidence, London 2013, pág. 442.

${ }^{19}$ Vid. su estricto -y sorprendente- funcionamiento en el antiguo periodo en LESSONA, Carlo, Teoría general de la prueba en Derecho Civil, Parte General, Trad. de Enrique Aguilera de Paz, Madrid 1928, págs. 118 y sigs.

${ }^{20}$ Bentham, Jérémie, Traité des preuves judiciaires, Paris 1823, t. II, Lib. VII, cap. XVI,pág. 163.

${ }^{21}$ DE FANO, Martino, Negativa qualiter probanda, en: “AAVV, Tractatus illustrium in utraque tum Pontificii, tum Caesarei iuris facultate Iurisconsultorum, De Probationibus”, T. IV, Venecia 1584,pág. 12, n. 3 ("Probandi facilitas transmittit onus probationis. Legitimatio personae standi in iudicio per quem probanda”): "Quarto fallit, quando illud quod negatur, esse quodmodo impossibilis probationis quo ad ipsum negantem, et facilis probationis quo ad adversarium. exemplum, si teneris mihi quolibet anno pro anima patris dicere unam missam, nam si allego te non dixisse hoc anno, impossibilis mihi esse talis probatio, et quo ad te facilis probatio censetur, merito tibi tale onus incumbit propter facilitatem. ad hoc induco Bald. in l. cum mulier in sua repeti solu matri.”
} 
hecho, es decir, lo que la doctrina posteriormente llamó facilidad probatoria ${ }^{22}$ o en Italia vicinanza probatoria ${ }^{23}$. Esa idea, obviamente, alteraba el original y estricto reparto.

En esa misma idea se basaron después las llamadas inversiones de la carga de la prueba ${ }^{24}$-que si bien se piensa no tienen nada de inversiones-, y aún más adelante esa idea cargada de inseguridad jurídica que constituye la llamada carga dinámica de la prueba ${ }^{25}$, que ha quedado reflejada en el art. 217.7 de la Ley de Enjuiciamiento Civil española ${ }^{26}$, o en el art. 167 del Código General del Proceso colombiano de $2012^{27}$ o en el art. 214 del Anteproyecto de Código Procesal Civil y Comercial de la Nación argentina de $2019^{28}$. En realidad, como vienen a reconocer estas

\footnotetext{
${ }^{22}$ Serra Domínguez, Manuel, Comentario al art. 1252 del Código Civil, en: "Comentarios al Código Civil y compilaciones forales” (dirigidos por Albaladejo), Madrid 1991, tomo XVI, vol. 2, págs. 66-68.

${ }^{23}$ Besso-MARCheis, "La vicinanza della prova”, Revista Eletrônica de Direito Procesual, v. 16, 2015, págs. 93 y sigs. En: http://www.e-publicacoes.uerj.br/index.php/redp/article/view/19962/14303

${ }^{24}$ Sobre el concepto, OrmaZABal SÁnchez, Discriminación y carga de la prueba en el proceso civil, Madrid 2011, págs. 62 y sigs.

${ }^{25}$ Peyrano, Jorge W (dir. y coautor), Cargas probatorias dinámicas, Buenos aires 2008, en especial págs. 13 y sigs, 19 y sigs y 75 y sigs.

${ }^{26}$ Artículo 217. Carga de la prueba. 1. Cuando, al tiempo de dictar sentencia o resolución semejante, el tribunal considerase dudosos unos hechos relevantes para la decisión, desestimará las pretensiones del actor o del reconviniente, o las del demandado o reconvenido, según corresponda a unos u otros la carga de probar los hechos que permanezcan inciertos y fundamenten las pretensiones.

2. Corresponde al actor y al demandado reconviniente la carga de probar la certeza de los hechos de los que ordinariamente se desprenda, según las normas jurídicas a ellos aplicables, el efecto jurídico correspondiente a las pretensiones de la demanda y de la reconvención.
}

3. Incumbe al demandado y al actor reconvenido la carga de probar los hechos que, conforme a las normas que les sean aplicables, impidan, extingan o enerven la eficacia jurídica de los hechos a que se refiere el apartado anterior.

4. En los procesos sobre competencia desleal y sobre publicidad ilícita corresponderá al demandado la carga de la prueba de la exactitud y veracidad de las indicaciones y manifestaciones realizadas y de los datos materiales que la publicidad exprese, respectivamente.

5. De acuerdo con las leyes procesales, en aquellos procedimientos en los que las alegaciones de la parte actora se fundamenten en actuaciones discriminatorias por razón del sexo, corresponderá al demandado probar la ausencia de discriminación en las medidas adoptadas y de su proporcionalidad.

A los efectos de lo dispuesto en el párrafo anterior, el órgano judicial, a instancia de parte, podrá recabar, si lo estimase útil y pertinente, informe o dictamen de los organismos públicos competentes.

6. Las normas contenidas en los apartados precedentes se aplicarán siempre que una disposición legal expresa no distribuya con criterios especiales la carga de probar los hechos relevantes.

7. Para la aplicación de lo dispuesto en los apartados anteriores de este artículo el tribunal deberá tener presente la disponibilidad y facilidad probatoria que corresponde a cada una de las partes del litigio.

${ }^{27}$ Artículo 167. Carga de la prueba. Incumbe a las partes probar el supuesto de hecho de las normas que consagran el efecto jurídico que ellas persiguen. No obstante, según las particularidades del caso, el juez podrá, de oficio o a petición de parte, distribuir la carga al decretar las pruebas, durante su práctica o en cualquier momento del proceso antes de fallar, exigiendo probar determinado hecho a la parte que se encuentre en una situación más favorable para aportar las evidencias o esclarecer los hechos controvertidos. La parte se considerará en mejor posición para probar en virtud de su cercanía con el material probatorio, por tener en su poder el objeto de prueba, por circunstancias técnicas especiales, por haber intervenido directamente en los hechos que dieron lugar al litigio, o por estado de indefensión o de incapacidad en la cual se encuentre la contraparte, entre otras circunstancias similares. Cuando el juez adopte esta decisión, que será susceptible de recurso, otorgará a la parte correspondiente el término necesario para aportar o solicitar la respectiva prueba, la cual se someterá a las reglas de contradicción previstas en este código. Los hechos notorios y las afirmaciones o negaciones indefinidas no requieren prueba.

${ }^{28}$ Artículo 214.- Carga de la prueba. Incumbirá la carga de la prueba a la parte que afirme la existencia de un hecho controvertido o de un precepto jurídico que el juez o el tribunal no tenga el deber de conocer. Incumbirá a cada una de las partes la carga de probar el presupuesto fáctico de las normas favorables a su 
normas, no se trata más que la mismísima facilidad probatoria designada con un nombre quizás más atractivo para algunos observadores. Pero en todo caso seguimos hablando de lo mismo: de la carga subjetiva y de sus matizaciones. Curioso a veces el empeño de la doctrina por complicar terminológicamente conceptos que bastantes problemas traen por sí mismos. Un último ejemplo de esta tendencia es la llamada por algunos autores tactical burden of the proof ${ }^{29}$, que significa ni más ni menos que conforme va avanzando el proceso y las partes exponiendo sus pruebas, dependiendo de la fuerza que pueda tener un argumento probatorio de una parte, la contraria se ve forzada a presentar un medio de prueba más convincente. Pura lógica de estrategia probatoria de cualquier proceso elevada a una categoría doctrinal que tampoco tiene la más mínima utilidad. Dicho de otro modo, seguimos en el ámbito de la carga subjetiva.

Sin embargo, todo lo anterior ya apunta al siguiente concepto, probablemente el más oscuro de todos los que afectan -podría decirse "aquejan"- a la carga de la prueba: la carga objetiva, originalmente denominada carga material ${ }^{30} \mathrm{o}$ carga de averiguación ${ }^{31}$, denominación esta última muy indicativa de lo que significa ${ }^{32}$. Con la misma se designaría, no al litigante que debe probar un hecho, sino directamente a los hechos que deben ser probados en el proceso para poder emitir el juicio. El concepto, según la concepción original de GLASER ${ }^{33}$, haría frente al riesgo de que el juez, al no poderse probar un hecho, dé por probado automáticamente el contrario. Ese riesgo lo sufriría el litigante beneficiado por ese hecho. Por tanto, la carga objetiva de la prueba consistiría en determinar, no a qué litigante le es más fácil probar un hecho -esa es la carga subjetiva-, sino a qué parte perjudicará la falta de prueba de un hecho.

Sin embargo, es muy importante saber que esa noción -algo extraña y en buena medida tautológica de la de carga subjetiva ${ }^{34}$ - provenía del proceso penal, y servía sobre todo para explicar por qué el acusado, sin tener la carga subjetiva de la prueba y por tanto sin tener que cumplir con la obligación de aportar medios de convicción, podía finalmente resultar condenado. Sea como fuere, el concepto pasó al terreno del proceso civil y sufrió una intensa

pretensión, defensa o excepción. No obstante, según las particularidades del caso, el juez podrá, de oficio o a petición de parte, distribuir la carga al ordenar las pruebas, exigiendo probar determinado hecho a la parte que se encuentre en una situación más favorable para aportar las evidencias o esclarecer los hechos controvertidos. Se considerará en mejor posición para probar a la parte en virtud de su cercanía con el material probatorio, por tener en su poder el objeto de prueba, por circunstancias técnicas especiales, por haber intervenido directamente en los hechos que dieron lugar al litigio, o por estado de indefensión o de incapacidad en la cual se encuentre la contraparte, entre otras circunstancias similares. A la parte a quien se imponga la carga se le otorgará el plazo suficiente para ofrecer la prueba.

${ }^{29}$ Gordon, Thomas F. / WALton, Douglas, “A formal model of legal proof standards and burdens”, en Emeren, F.H. van (Ed.); Garssen, B. (Ed.); Godden, D. (Ed.); Meuffels, B. (Ed.) ; International Society for the Study of Argumentation -ISSA-:7th Conference of the International Society for the Study of Argumentation 2010. Proceedings: Amsterdam, June 29 to July 2, 2010, Amsterdam: Sic Sac, 2011, págs. 644 y sigs. Prakken, H. / SARTor, G., “A Logical Analysis of Burdens of Proof”. en Kaptein, H. / PrakkEn, H. Nerheij, B. (Eds.), Legal Evidence and Proof: Statistics, Stories, Logic, Farnham 2009, págs. 223 y sigs. BEX, F. / WAlton, D., "Burdens and standards of proof for inference to the best explanation: three case studies”, Law, Probability and Risk 11, 2012, pág. 118.

${ }^{30}$ GLASER, Julius, Handbuch des Strafprozesses, vol. I, 1883, pág. 364.

${ }^{31}$ Sobre la cuestión terminológica, vid. RoSENBERG, Die Beweislast, cit. págs. 26-27.

${ }^{32}$ RosenBerg, Die Beweislast, cit.pág. 34.

${ }^{33}$ GLASER, Julius, Handbuch des Strafprozesses, vol. I, 1883, pág. 364.

${ }^{34}$ La carga subjetiva indica a qué parte le es más fácil probar un hecho y, si no lo hace, esa será la parte perjudicada por la falta de prueba del hecho, lo que es la carga objetiva pero supone una identidad con la carga subjetiva en gran medida, con la principal excepción del acusado en el proceso penal, como vamos a ver. 
reelaboración por parte de ROSENBERG ${ }^{35}$, que es quien, en mi opinión, le da auténtico contenido aunque también aquel que, llevando la lógica de sus ideas hasta el final, le acaba sustrayendo ese contenido, como vamos a ver.

Dice ROSENBERG ${ }^{36}$, hablando de la carga subjetiva de la prueba, que el concepto inicial habría evolucionado en el sentido de superar la concepción original de onus probandi en el sistema de prueba legal. En ese sistema, como se explicará después, los pleitos se decidían en función de si cada parte había aportado o no sus pruebas, y no en razón de su valoración. Es decir, se verificaba solamente si la parte demandante había aportado su prueba y la demandada la suya. Y después, para ver quién ganaba el proceso, se pesaba o sumaba la prueba aportada por cada parte en función de los estándares plena probatio y semiplena probatio que veremos en el siguiente epígrafe, pero nada más, es decir, no se valoraba realmente -es decir, racionalmentela prueba.

Pues bien, ROSENBERG ${ }^{37}$ nos dice que a partir de la introducción de la frase "unter Berücksichtigung des gesamten Inhalts der Verhandlungen “38 en el $\$ 286 \mathrm{ZPO}^{39}$, ya habría dejado de importar quién aportaba la prueba, sino que el tribunal la valoraría con independencia de ese hecho, es decir, tomaría en consideración todo el material aportado por las partes sin tener en cuenta cuál de ellas lo había aportado. Ese precepto, por cierto, fue el que introdujo el sistema de libre valoración en Alemania. Y estamos también ante la tenebrosa génesis que nunca explicó CHIOvENDA ${ }^{40}$-que lo expuso sin citarlo- del llamado "principio de adquisición" por las doctrinas italiana ${ }^{41} \mathrm{e}$ hispana, que es importantísimo en la materia que estamos analizando. Ese origen no es más que la consecuencia lógica de la introducción del sistema de libre valoración. Con el mismo se dejaba atrás el antiguo sistema -el de prueba legal- y se introducía el nuevo, el de libre valoración, en el que el onus probandi -la carga subjetiva- había dejado de tener, como se acaba de evidenciar, sentido alguno. Ya no importaba en absoluto qué litigante aportaba las pruebas al proceso. En ese momento debió haberse eliminado por la doctrina el concepto de carga de la prueba porque era una pieza de un sistema, el legal, que en gran medida había dejado de existir.

Hubo quien señaló esta fatal consecuencia en su día ${ }^{42}$, pero $\mathrm{WACH}^{43}$, siendo muy joven ${ }^{44}$, descalificó con evidente soberbia a quien sostuvo esa tesis, muy probablemente por considerar

\footnotetext{
${ }^{35}$ RosenBERg, Die Beweislast, cit. págs. 34 y sigs.

${ }^{36}$ RosenBERG, Die Beweislast, cit. págs. 28 y sigs.

${ }^{37}$ RosenBERG, Die Beweislast, cit.pág. 30.

${ }^{38}$ Traducción: "considerando el contenido global de las actuaciones".

${ }^{39}$ \286 Freie Beweiswürdigung. (1) Das Gericht hat unter Berücksichtigung des gesamten Inhalts der Verhandlungen und des Ergebnisses einer etwaigen Beweisaufnahme nach freier Überzeugung zu entscheiden, ob eine tatsächliche Behauptung für wahr oder für nicht wahr zu erachten sei. In dem Urteil sind die Gründe anzugeben, die für die richterliche Überzeugung leitend gewesen sind. (2) An gesetzliche Beweisregeln ist das Gericht nur in den durch dieses Gesetz bezeichneten Fällen gebunden.

${ }^{40}$ Chiovenda, Giuseppe, Principi di Diritto Processuale, 3 ${ }^{a}$ ed. Napoli 1923,pág. 748.

${ }^{41}$ Vid. TARUFFO, M., "La valutazione delle prove”, en AAVV (dir. TARUFFO), La prova nel processo civile, Milano 2012, en la serie Cicu / Messineo / MEngoni / SChlesinger, Trattato di Diritto civile e commerciale págs. 249 y sigs.

${ }^{42}$ KoHLER, Josef (con HolTZENDORFF), Encyclopädie der Rechtswissenschaft, vol. 3, Leipzig 1904, págs. 315 y sigs. BAR, L., Recht und Beweis im Zivilprozesse, Leipzig 1867, págs. 46 y sigs.

${ }^{43}$ WACH, Adolf, Der Entwurf einer deutschen Civilprozeßordnung, Kritische Vierteljahresschrift für Gesetzgebung und Rechtswissenschaft vol. 141872,pág. 357: „Eine der größten Thorheiten der Reformjurisprudenz ist die Behauptung, die freie Beweistheorie führe zur Beseitigung der Grundsätze
} 
que la misma abría las puertas a la vigencia del principio inquisitivo en el proceso ${ }^{45}$, cuando no es así. Sea como fuere, es muy probable que WACH influyera en buena parte de la doctrina por la difusión de sus ideas, y también en ROSENBERG en este particular -no así en otros muchos aspectos del mismo tema- cuando este redactó la primera versión de su libro al respecto en 1900. De hecho, WACH, entre otros, recensionó el libro de ROSENBERG en $1925^{46}$ y consta que se conocían ${ }^{47}$. Quién sabe si esas circunstancias influyeron en ROSENBERG para perpetrar un auténtico acto de nostalgia científica difícilmente explicable, reafirmando con mayor influencia que ningún otro autor la idea de GLASER. Y así se dispuso, primero, a no plantear sorprendentemente- la abolición del concepto de carga subjetiva -pese a lo que había dicho al respecto- y, segundo -en contra de la opinión de $\mathrm{WACH}^{48}$-, a asentar el concepto de carga objetiva o de carga de averiguación, que debe hacerse notar que no es sino una consecuencia de la abolición del concepto de carga subjetiva y que, en el fondo, trata de mantener doctrinalmente esa antigua idea aunque sea pendiente de un hilo. Y así afirmó que aunque ya no interesaba, en realidad, quién había aportado la prueba en el proceso a efectos de valoración, aún era interesante determinar a quién iba a perjudicar la falta de prueba de un hecho con independencia de su actuación en el proceso. Y ese es el único contenido de la carga objetiva. No tiene más ${ }^{49}$.

Y digo que no tiene más porque a partir de ese momento, como viene a reconocer el propio ROSENBERG, el concepto se separa definitivamente de la definición de "carga", porque en realidad la carga no la tiene nadie, sino que sin la prueba de esos hechos, no es que el proceso no pueda resolverse, sino que, en verdad, la noción de carga objetiva supera por completo el reparto de responsabilidades probatorias entre los litigantes y describe un espacio de incógnitas fácticas que debieran ser resueltas para poder emitir el juicio jurisdiccional. El concepto podría ser relevante en los procesos en los que puede practicarse prueba de oficio, porque de algún modo puede decirse que sirve para orientar la labor del juez -aunque estaría perfectamente orientada sin el mismo, como se verá después-, pero fuera de ello sólo marca el campo de actuación de la carga subjetiva, lo que provoca la -casi completa-tautología a la que

über Vertheilung der Beweislast. Sie beruht auf einer groben Verwechslung des inquisitorischen Princips des Strafprocesses, der Pflicht des Richters zur selbstthätigen Beschaffung der Beweise und der Emancipation von Beweisregeln bei Beurtheilung des von der Parteien gelieferten Materials. Die vielgehörte Erwägung, weil der Richter aus dem Ergebnis der ganzen Verhandlung unter Würdigung aller Umstände sich seine Ueberzeugung zu bilden habe, so kann nur noch darauf ankommen, ob bewiesen ist, nicht wer zu beweisen und beweisen habe, ist ein Trugschlug. Dem Richter kann es allerdings gleich sein, wer bewiesen hat, wenn bewiesen ist, aber nicht wer zu beweisen hatte, wenn nicht bewiesen ist. Die Sätze actore non probante reus absolvitur und reus excipiendo actor fit bleiben unerschüttert (...)“.

${ }^{44}$ Había nacido en 1843 en Kulm (la actual Chełmno), por lo que en el momento de publicarse su escrito tenía 29 años.

${ }^{45} \mathrm{Se}$ deduce claramente del texto de la nota anterior. WACH, Der Entwurf einer deutschen Civilprozeßordnung, cit. págs. 331 y sigs, 357-358.

${ }^{46}$ WACH, Adolf, “Rez. Rosenberg, Beweislast, 2. Auflage“, Juristische Wochenschrift, 54, 1925,pág. 722.

${ }^{47}$ GRÄFE, Ulrike, Leo Rosenberg - Leben und Wirken (1879-1963), Berlin 2011, págs. 46 y sigs.

${ }^{48}$ WACH, „Beweislast nach dem BGB“, ZZP, 29, 1901, págs. 363-364., definió la carga material como un "gegenstandsloser Begriff“, es decir, un concepto sin objeto.

${ }^{49}$ Vid. el propio RosenBerg, Leo, Lehrbuch des Deutschen Zivilprozeßrechts, Berlin 1929,pág. 368. Y detrás de él, toda la manualística: PoHLMAnN, Petra, Zivilprozessrecht, München 2014,pág. 153, LÜKE, Wolfgang, Zivilprozessrecht, München 2011,pág. 273, JAUERnIG, Othmar / Hess, Burkhard, Zivilprozessrecht, München 2011, págs. 202-203. Musielak, Hans-Joachim, Grundkurs ZPO, München 2002,pág. 279. GrUNSKY, Zivilprozessrecht, Bielefeld 2003, pág. 40. SchILKEN, Eberhard, Zivilprozessrecht, München 2006, págs. 271272, o la propia edición actual del manual de RosenBERG: RosenBERG / SCHWAB / GoTTWALD, Zivilprozeßrecht, München 2018,pág. 697. 
antes me referí. Es decir, la carga objetiva expresaría los hechos que deben probarse, y la subjetiva quién debe hacerlo. Por ello se ha dicho que en un orden lógico primero se considera la carga objetiva, y después la subjetiva ${ }^{50}$.

Pero como decía, ello obscurece definitivamente el concepto de "carga", alejándolo por completo del originario onus probandi. Con el concepto de "carga" objetiva estamos más bien ante un listado de hechos a probar, y que deben ser demostrados a través de los medios de prueba que serán objeto de valoración judicial. Y es justo en ese punto en el que se abre la pregunta de qué fuerza debe tener la prueba que se obtenga en el proceso para satisfacer la convicción judicial. Es como si de repente, la palabra "carga", de designar una especie de "obligación” para las partes, adoptara una significación más literal y pasara directamente a ser un "peso" que debe tener la prueba para ser convincente.

Sin embargo, se trata de un salto argumental realmente insalvable, porque se pasa de la cuestión de quién aporta la prueba a su valoración, que son cosas absolutamente diferentes y que sólo cabría relacionar, como veremos después, en un sistema de prueba legal en el que, precisamente, la cuestión de quién aporta la prueba, no es sólo que asista a la valoración del juez, sino que sustituye a dicha valoración ${ }^{51}$. De esa consciencia implícita viene que ROSENBERG ${ }^{52}$, completamente orientado por el sistema de valoración libre y tratando de superar el legal, dijera que las normas de carga de la prueba no son necesarias cuando el hecho es notorio, cuando ha sido confesado por un litigante o cuando un juez utiliza máximas de la experiencia para construir su convicción.

Poco a nada consciente fue ROSENBERG de las consecuencias de esta última frase, que influyó, por cierto, en el art. 139 de Código General del Proceso de Uruguay de $1988^{53}$ o en parte en el art. 136 del Código Procesal Civil boliviano de $2013^{54}$. Si la incógnita sobre los hechos se resuelve a través de máximas de experiencia, es decir, a través del razonamiento lógico del juez expresando en su sentencia la impresión que le provoca la práctica del medio de prueba, se acaba sustituyendo a la carga -ahora objetiva- de la prueba por el sistema de libre valoración. Algo querrá decir que LAUMEN ${ }^{55}$, recogiendo la opinión de BENDER, NACK y TREUER ${ }^{56}$, reconozca que casi todas las pruebas -salvo el reconocimiento judicial- son indirectas, es decir, indicios ${ }^{57}$.

\footnotetext{
${ }^{50}$ Vid. Rosenberg / SchWAB / GotTWALD, Zivilprozeßrecht, München 2018,pág. 697, LAUMEN, Hans-Willi, „Grundbegriffe der Beweislast“, en Baumgärtel / Laumen / Prütting, Handbuch der Beweislast, München 2009, págs. 42-43.

${ }^{51}$ Es absolutamente fundamental leer a TARUFFo, Michele, Studi sulla rilevanza della prova, Padova 1970, págs. 14-18, para entender hasta sus últimas consecuencias los antecedentes y esencia de lo que acabo de afirmar, que también confundieron a Micheli, Gian Antonio, en su L’onere della prova, Padova 1966, págs. 141 y sigs.

${ }^{52}$ RoSENBERG, Die Beweislast, cit. pág. 55.

${ }^{53}$ Artículo 139.- Carga de la prueba. 1 Corresponde probar, a quien pretende algo, los hechos constitutivos de su pretensión; quien contradiga la pretensión de su adversario tendrá la carga de probar los hechos modificativos, impeditivos o extintivos de aquella pretensión.

2. La distribución de la carga de la prueba no obstará a la iniciativa probatoria del tribunal ni a su apreciación, conforme con las reglas de la sana crítica, de las omisiones o deficiencias de la prueba.

${ }^{54}$ Artículo 136. (carga de la prueba). I Quien pretende un derecho, debe probar los hechos constitutivos de su pretensión. II. Quien contradiga la pretensión de su adversario, debe probar los hechos impeditivos, modificatorios o extintivos del derecho de la parte actora. III. La carga de la prueba que el presente Código impone a las partes no impedirá la iniciativa probatoria de la autoridad judicial.

${ }^{55}$ LAUMEN, „Grundbegriffe der Beweislast“, cit. pág. 308.
} 
No deja de resultar curioso, y hasta revelador, que ROSENBERG en la página inmediatamente anterior ${ }^{58}$ de su obra diga que no se puede distinguir la respuesta a la pregunta "¿qué se debe probar?" de la que tenga la pregunta “iquién debe probar?”, ya que la respuesta a la primera pregunta da la respuesta también a la segunda, dado que no se puede separar la respuesta a ambas preguntas. De ese modo, carga objetiva y subjetiva irían de la mano. Es también revelador que cambiando de sistema jurídico, el concepto complementario al de burden of production en el Common Law sea el de burden of persuasion -o persuasive burden o probative burden en el Reino Unido ${ }^{59}$-, pensado sobre todo para el jurado, y que justamente el mismo se centre en qué "estándares de prueba" deben alcanzarse para dar por probado un hecho en cada proceso. Es decir, como vamos a ver en el apartado siguiente, qué niveles de convicción debe tener el juez para dar por probado un hecho ${ }^{60}$. Y ello conduce al paso final no tan claramente dado por la doctrina alemana: se acaba identificando la carga de la prueba con la valoración de la misma, lo que deja sin contenido al concepto de carga objetiva y al de burden of persuasion. Es decir, bajo ambas nociones se está describiendo en realidad la valoración de la prueba, centrándose en el nivel de convicción, es decir, en la propia esencia de la valoración de la prueba.

En consecuencia, el concepto, o deja de llamarse "carga" -salvo que se la identifique con un peso, como se dijo-, o simplemente se convierte en redundante del de valoración.

Pero se deduce aún otra consecuencia importante del concepto de carga objetiva a la que ya se hizo referencia pero que merece la pena recordar, y que es un nuevo resultado del sistema de libre valoración y que supera la versión originaria del principio dispositivo en el que estaba basado el sistema legal como forma de controlar al juez. En el proceso se identifican hechos que deben probarse pero, como hemos visto, por mor del principio de adquisición ya no importa quién los traiga, de manera que las pruebas aportadas por una parte y que en principio le benefician, pueden contener detalles que acaben beneficiando a la parte contraria. Y ello es relevante a efectos de valoración, porque lo que importa es que el hecho sea objeto de prueba para esclarecerlo, con independencia de quién contribuya a aclararlo, que como ya se dijo era lo único que importaba en el sistema de prueba legal. Sucede constantemente que un documento tiene detalles que pueden beneficiar al adversario, o bien que un testigo se convierte en hostil. Y ello no importa, puesto que la información que aportan esos medios de prueba es útil para el proceso, con independencia de quién aporte la prueba. Todo lo descrito, ya se ha dicho, es el llamado desde CHIOvenda "principio de adquisición", que curiosamente ha sido objeto de un estudio bastante superficial, dado que su contenido se considera simplemente lógico ${ }^{61}$.

\footnotetext{
${ }^{56}$ Bender, Rolf / NACK, Armin / TREUER, Wolf-Dieter, Tatsachenfeststellung vor Gericht, München 2007, pág. 145.

${ }^{57}$ Enfoque ya expresado en BENDER, Rolf / NACK, Armin, Grundzüge einer Allgemeinen Beweislehre, Deutsche Richterzeitung 1980,pág. 121 y que comparte con MuÑoz SABATÉ, Lluís, Técnica probatoria, 3a ed., Barcelona 1993, pág. 20.

${ }^{58}$ ROSENBERG, Die Beweislast, cit. pág. 54.

${ }^{59}$ DenNis, The Law of Evidence, cit. pág. 441.

${ }^{60} \mathrm{BEX} /$ WALTON, "Burdens and standards of proof for inference to the best explanation: three case studies", cit. pág. 113, 117.

${ }^{61}$ Vid. nuevamente TARUFFO, Studi sulla rilevanza della prova, cit. págs. 14-18.
} 
Y en realidad, lo es. Es una simple consecuencia del sistema de libre valoración, en el que se espera de las partes que colaboren con el juez en el esclarecimiento de los hechos ${ }^{62}$, y no solamente que aporten medios de prueba que les beneficien, como ocurría bajo el dominio del sistema de prueba legal. Y es que finalmente el proceso, en nuestra época, se ha convertido en lo que nunca debió dejar de ser: un espacio que ponga al juez en las mejores condiciones para recibir las alegaciones de las partes y la prueba de los hechos, valorándolos libremente sin recurrir a los atajos de la carga subjetiva de la prueba, que muchas veces provocan resultados absurdos.

Con ello se completa una evolución, pero a la vez desaparece un concepto ${ }^{63}$. Bajo el sistema de prueba libre, la utilidad de la carga objetiva se identifica con la valoración de la prueba, y la carga subjetiva deja de tener sentido con el principio de adquisición. Era quizás el único destino posible para dos instituciones que derivaban del sistema legal y tenían su lógica en ese sistema. Lo vamos a ver a continuación.

\section{Concepto y variedades de estándares de prueba.}

Hay que profundizar en los entresijos de esa "carga" objetiva, tan similar a la burden of persuasion si se mira la esencia de ambas y no se atiende solamente a las definiciones doctrinales que sólo hacen que disponer fronteras artificiales entre nociones análogas o idénticas.

A lo largo de la historia y en diversas culturas jurídicas ha existido la referencia a los que actualmente se llaman, por influencia anglosajona, "estándares de prueba" ${ }^{64}$. Resulta sumamente interesante tomar en consideración que se trata de una temática abordada recurrentemente, a veces de manera cerrada y otras de modo más abierto, como sucede actualmente. Se ha llegado a decir que "standards of proof are a simple concept, unless you stop to think about them." ${ }^{65}$ No es una mala orientación de partida, aunque quizás sea errónea en su destino.

Los primeros en surgir en la historia fueron los estándares del sistema de prueba legal. Conocía solamente dos de esos estándares ${ }^{66}$, más un tercero que a veces se citaba pero que tenía una definición sumamente imprecisa para el proceso penal. Me refiero a la plena probatio, la semiplena probatio y, finalmente, a ese tercer estándar que conocían algunos autores llamado

\footnotetext{
${ }^{62}$ Rosenberg, Leo / Schwab, Karl Heinz / GotTwAld, Peter, Zivilprozessrecht, cit. págs. 427-428.

${ }^{63}$ Lo apuntó o intuyó en su día MuÑOz SABATÉ, Lluís, Técnica probatoria, Barcelona 1967, pág. 46.

${ }^{64}$ Una perspectiva comparatista, aunque con errores, puede verse en CLERMONT, K.M. / SHERWIN, E., “A Comparative View of Standards of Proof”, American Journal of Comparative Law 50, n. 2, primavera 2002, págs. 243 y sigs. Vid. los errores de este artículo señalados y debidamente subsanados por TARUFFO, M., "Rethinking the Standards of Proof", American Journal of Comparative Law 51, n. 3 verano 2003, págs. 659 y sigs. Vid. también Clermont, K. M., “Standards of Proof Revisited”, Cornell Law Faculty Publications, 13, 2009, págs. 469 y sigs.

${ }^{65}$ Clermont, K.M., "Staying Faithful to the Standards of Proof”, Cornell Legal Studies Research Paper n. 1845, 2018,pág. 2.

${ }^{66}$ Cfr. OrTiZ De ZúÑIgA, Práctica general forense, T. II, Madrid 1856, págs. 239, 255, 257 y especialmente 271. De Vicente y Caravantes, Tratado histórico, crítico filosófico de los procedimientos judiciales en materia civil según la nueva Ley de Enjuiciamiento, Madrid 1856, pág. 133.
} 
probatio plenissima, al que apenas me referiré por ser extraordinariamente impreciso su contenido ${ }^{67}$.

La plena probatio fue el estándar de convicción -en principio- máxima que se podía alcanzar en el proceso. Se llegaba al mismo disponiendo de un documento público -muchas veces se decía cuál debía ser exactamente ${ }^{68}$, o bien dos testigos presenciales, o bien a través del juramento. En realidad, en todo caso se trataba de un mismo trasfondo: el juramento. Y es que detrás de un documento público había un fedatario que juraba que era cierto, o bien los dos testigos juraban, o bien el propio litigante juraba. Por tanto, se trataba de un estándar netamente religioso para ser exactos, que hacía depender la convicción judicial de la fe, lo que lo relacionaba con la ordalía. De hecho, el juramento es una civilización de esa ordalía que suprimía el bestialismo ${ }^{69}$. Y como se ha dicho, el nivel de convicción es máximo ${ }^{70}$. En la época no se podía dudar de la fe, esto es, de la voluntad de la divinidad.

La semiplena probatio era todo lo demás, es decir, el documento privado, un solo testigo -o testigos de referencia- o un litigante que afirmaba sin jurar. Ello daba lugar a los indicios, más tarde incluídos en el estudio de las presunciones. En este punto la valoración de estas pruebas hubiera debido de ser libre, pero en realidad se acababa sumando simplemente el número de pruebas semiplenas ${ }^{71}$, sin valorarlas en absoluto a través de la lógica. En todo caso, se trataba de un nivel de convicción menor que el anterior. Es por ello por lo que en el proceso penal se prohibieron los testigos de referencia ${ }^{72}$, e incluso con frecuencia la "prueba de indicios" ${ }^{73}$, porque se trataba de obtener la plena probatio, es decir, un nivel de convicción máxima que permitiera alcanzar las exigencias de ULPIANO ${ }^{74}$ de no condenar por sospechas, sino por lo que más adelante se llamaron "pruebas directas". De hecho, la probatio plena era la única prueba directa, siendo indirecta el resto, es decir, la semiplena probatio.

Se trata, sin duda, del primer intento de estandarización de la valoración de la prueba, a fin de controlar más que de ayudar al juez, huyendo de su conciencia o intuición y haciendo que lo que ocurriera en el proceso fuera patrimonio de las partes, como pretendió con éxito el remoto

\footnotetext{
${ }^{67}$ NÖRR, Romanisch-kanonisches Prozessrecht, cit.pág. 129. La clasificación de plenissima, plena y semiplena era de Azzone, Summa Azonis, Venecia 1581, lib. III, 1 (De iudicis), 18, 19. Durante, Speculum iuris, Venecia 1602, lib. I, Part. I, De summaria cognitione, 1, 2 y 3.

${ }^{68}$ Siguiendo las indicaciones del Codex sobre todo, aunque luego las leyes de cada territorio concretaban esos documentos a su realidad. Vid. Partida III, Tít. 18.

${ }^{69}$ Lo explico en Nieva FenOLL, La valoración de la prueba, cit. págs. 41 y sigs.

${ }^{70}$ GARnOt, B., "Voltaire et la justice d'ancien régime: la médiatisation d'une imposture intellectuelle”, Nouveau Monde Éditions, 2010, n. 15, pág. 29.

${ }^{71}$ Vid. JAUMAR y CARRera, Joaquín, Práctica forense, Barcelona 1840, pág. 48: "Por regla general el conjunto de dos pruebas semiplenas equivale á una de plena, pero carecen de esta fuerza en las causas criminales y aun en las civiles cuando obsta á las dos semiplenas una de plena.” NöRR, Romanisch-kanonisches Prozessrecht, Heidelberg 2012, pág. 128.

${ }^{72}$ Partida III, tít. XVI, Ley 28. Constitutio criminalis Carolina de 1532, art. 65: Art. 65. Wie zeugenn sagen sollen. Jtem die zeugen sollenn sagen von jrem selbs eigen waren wissenn mit antzeigung jrs wissens gruntlicher vrsach. So sy aber vonn frembden hören sagenn wurden, das soll nit genugsam geacht werden.

${ }^{73}$ Partida III, tít. XIV, Ley 12.

${ }^{74}$ Dig. L. 48, tít. 19, 5. Ulpiano: “sed nec de suspicionibus debere aliquem damnari divus traianus adsidio severo rescripsit: satius enim esse impunitum relinqui facinus nocentis quam innocentem damnari.”
} 
secundum allegata et probata $\left(\right.$ partium $\left.^{75}\right)$. Pero paralelamente, ya en el siglo XVIII, en el mundo del Common Law surgió un estándar para el proceso penal que tendría un larguísimo recorrido, llegando hasta nuestros días, y que en su origen sólo buscó orientar a los jurados. Es el beyond any reasonable doubt o "más allá de toda duda razonable" ${ }^{76}$, en expresión española, no hay que negarlo, un tanto pintoresca, aunque recogida en estos términos por el art. 340 del Código Procesal Penal chileno de $2000^{77}$ o por el art. 359 del Código Nacional de Procedimientos Penales mexicano de $2014^{78}$.

Se trata de un estándar que está demostrado ${ }^{79}$ que surgió de otro estándar anterior del Derecho canónico: la certeza moral ${ }^{80}$. La misma supone que si un proceso se celebra de acuerdo con lo alegado y probado en el proceso -aspecto objetivo- ante un juez debidamente instruido que actúe racionalmente -aspecto subjetivo-, quizás no podamos asegurar que averigüemos la verdad en el proceso, pero tendremos la "certeza moral" de haberlo hecho. Pues bien, con el más allá de toda duda razonable se trataría de expresar en una frase las bondades de ese concepto de un modo comprensible, de manera que se transmitiera a los jurados la idea de que tenían que estar muy seguros de la culpabilidad de un reo para condenarle ${ }^{81}$. Es decir, que la condena sólo procedía con una máxima seguridad de la convicción que sienta cada jurado, esto es, con una parte esencial -el aspecto objetivo- de esa certeza moral. En la época en que se enunció, el beyond any reasonable doubt no fue, por tanto, realmente pensado como un estándar máximo, aunque luego se convirtiera en dicho estándar, sino como una simple instrucción para jurados. No es de extrañar que poco después los revolucionarios franceses lo expresaran en traducción libre ${ }^{82}$ como intime conviction, expresión que ya tenía cierto uso en Francia antes de ese momento ${ }^{83}$. En realidad, se trataba de que expresaran su convicción según the best of their knowledge, expresión inglesa corriente que está en la base de la concepción moderna del sistema de libre valoración ${ }^{84}$.

\footnotetext{
${ }^{75}$ Sobre el "partium" me remito a cuanto indiqué en NIEVA FENOLL, "El mal nombre del principio inquisitivo”, en La ciencia jurisdiccional: novedad y tradición, Madrid 2016, págs. 30 y sigs.

${ }^{76}$ Vid. DALIA, Gaspare, Convincimento giudiziale e ragionevole dubbio, Milano 2018, págs. 1 y sigs.

${ }^{77}$ Artículo 340.- Convicción del tribunal. Nadie podrá ser condenado por delito sino cuando el tribunal que lo juzgare adquiriere, más allá de toda duda razonable, la convicción de que realmente se hubiere cometido el hecho punible objeto de la acusación y que en él hubiere correspondido al acusado una participación culpable y penada por la ley.

El tribunal formará su convicción sobre la base de la prueba producida durante el juicio oral.

No se podrá condenar a una persona con el solo mérito de su propia declaración.

${ }^{78}$ Artículo 359. Valoración de la prueba El Tribunal de enjuiciamiento deberá hacer referencia en la motivación que realice, de todas las pruebas desahogadas, incluso de aquellas que se hayan desestimado, indicando las razones que se tuvieron para hacerlo. La motivación permitirá la expresión del razonamiento utilizado para alcanzar las conclusiones contenidas en la resolución jurisdiccional. Sólo se podrá condenar al acusado si se llega a la convicción de su culpabilidad más allá de toda duda razonable. En caso de duda razonable, el Tribunal de enjuiciamiento absolverá al imputado.

${ }^{79}$ Whitman, James Q., The origins of reasonable doubt, New Haven y London 2005, págs. 187 y sigs.

${ }^{80}$ Llobell TuSET, Joaquín, La certezza morale nel processo canonico matrimoniale, en: "Il Diritto Ecclesiástico, 109/1, 1998,pág. 771. Aliste SANTOS, Relevancia del concepto canónico de "certeza moral”, cit. págs. 667-668, y del mismo autor, La motivación de las resoluciones judiciales, cit. págs. 309 y sigs.

${ }^{81}$ Así se hizo hacia 1780 en el Old Bailey de Londres, como relata WHITMAN, The origins of reasonable doubt, cit.pág. 187.

${ }^{82} \mathrm{La}$ primera vez que lo hicieron, al traducir la obra de BlACKSTONE, Commentaires sur les loix angloises, traduits de l'Anglois par Auguste-Pierre Damiens de Gomicourt sur la quatrieme edition d'Oxford, t. V, Bruselas 1776, pág. 176, lo tradujeron simplemente como “connoisance” (sic).

${ }^{83}$ Vid. por ejemplo, DE LA Tour, Bertrand, Oeuvres, Colonia 1776, pág. 41.

${ }^{84}$ Blackstone, Commentaries on the Laws of England, III, London 1794, cap. 23, págs. 373-374: “As to such evidence as the jury may have in their own consciences, by their private knowledge of facts, it was an
} 
Pero conforme fue pasando el tiempo, el mundo del Common Law sintió -aunque no unánimemente ${ }^{85}$ - la necesidad de determinar mejor los niveles de convicción a fin de intentar evitar -creo que vanamente- veredictos erróneos, y así surgieron la "probabilidad preponderante" - preponderance of evidence- ${ }^{86} \mathrm{o}$ balance of probabilities en el Reino Unido ${ }^{87} \mathrm{y}$ la clear and convincing evidence ${ }^{88}$. La primera sería el estándar mínimo para dar por probado un hecho en una sentencia, que podría representarse intuitivamente con un porcentaje del 50,01\% de convicción ${ }^{89}$. El segundo sería más exigente, pero un escalón por debajo del "más allá de toda duda razonable”. Surgen así, como se ve, tres estándares que recuerdan muy poderosamente a la semiplena probatio y a la probatio plena, quedando el beyond any reasonable doubt en el terreno de una especie de probatio plenissima, tan difícil de definir como aquel antiguo concepto ${ }^{90}$. También se ha hablado de estándares inferiores a la preponderance of evidence, que sirven sobre todo en el proceso penal para iniciar actuaciones policiales. El más conocido sin duda es el de la probable cause ${ }^{91}$, pero se han desarrollado algunos más sobre todo en la jurisprudencia estadounidense, pero que no son ni tan conocidos ni tan utilizados.

Finalmente, en Alemania habla la doctrina de la medida de prueba - Beweisma $\beta-{ }^{92}$. Se trata de diferentes medidas de prueba en realidad, y ofrecen también distintos niveles de convicción

ancient doctrine, that this had as much right to sway their judgment as the written or parol eyidence which is delivered in court. And therefore it hath been often held, that though no proofs be produced on either side, yet the jury might bring in a verdict. For the oath of the jurors, to find according to their evidence, was construed to be, to do it according to the best of their own knowledge. This seems to have arisen from the ancient practice in taking recognitions of assise, at the first introduction of that remedy; the sheriff being bound to return such recognitors as knew the truth of the fact, and the recognitors, when sworn, being to retire immediately from the bar, and bring in their verdict according to their own personal knowledge, without hearing extrinsic evidence or receiving any direction from the judge. And the same doctrine (when attaints came to be extended to trials by jury, as well as to recognitions of assise) was also applied to the case of common jurors; that they might escape the heavy penalties of the attaint, in case they could shew by any additional proof, that their verdict was agreeable to the truth, though not according to the evidence produced: with which additional proof the law presumed they were privately acquainted, though it did not appear in court. But this doctrine was again gradually exploded, when attaints began to be disused, and new trials introduced in their stead. For it is quite incompatible with the grounds upon which such new trials are every day awarded, viz. that the verdict was given without, or contrary to, evidence. And therefore, together with new trials, the practice seems to have been first introduced, which now universally obtains, that if a juror knows any thing of the matter in issue, he may be sworn as a witness, and give his evidence publicly in court.”

${ }^{85}$ Son bien conocidas las críticas de Wigmore, John Henry, A Treatise on the System of Evidence in Trials at Common Law, vol. IV, Boston 1905, §2497-2498, págs. 3540-3547, sobre el particular.

${ }^{86}$ Redmayne, M., “Standards of Proof in Civil Litigation”, Modern Law Review 62, no. 2, Marzo 1999, págs. 167 y sigs.

${ }^{87}$ MURPHY, Peter, Murphy on evidence, Oxford 2005, pág. 102

${ }^{88}$ Redmayne, M., “Standards of Proof in Civil Litigation”, cit. pág. 187.

${ }^{89}$ GuErra, A. / LuPPI, B. / PARISI, F., "Standards of Proof and Civil Litigation: A Game-Theoretic Analysis", The B.e. Journal of Thworetical Economics, 2019, p 2.

${ }^{90}$ Laudan, Truth, error and Criminal Law, cit. págs. 29 y sigs. DoAK, Jonathan /McGourlay, Claire, Criminal evidence in context, London - New York 2009, págs. 58 y sigs. KeANE, Adrian, The modern law of evidence, London 2000, págs. 92 y sigs. CHOo, Andrew L-T, Evidence, Oxford 2009, pág. 49.

${ }^{91} \mathrm{IV}$ enmienda de la Constitución de los EEUU. Sobre el mismo, MirandA EsTRAMPES, M., Prueba ilícita y regla de exclusión en el sistema estadounidense. Crónica de una muerte anunciada, Madrid 2019, págs. 17 y sigs.

${ }^{92}$ LeIPOLD, Dieter, Beweismaß und Beweislast im Zivilprozeß, Berlin 1985. GotTwALD, Das relative Beweismaß im englischen und deutschen Zivilprozeß, FS Henrich 2000, págs. 165 y sigs. SCHWEIZER, 
que en parte son conocidos por el Derecho continental y en parte por el Common Law. De este último se ha adoptado la probabilidad preponderante -Überwiegensprinzip- ${ }^{93}$ y el más allá de toda duda razonable, como estándares de convicción respectivamente del proceso civil y del proceso penal, pero existe un tercer estándar que es la Glaubhaftmachung ${ }^{94}$, que equivaldría a la prueba prima facie del Derecho español o italiano entre otros. Significa este último un estándar mínimo de convicción, suficiente para la adopción de medidas cautelares en general, salvo las más graves del proceso penal, que requieren un grado de convicción superior. Se discute si debe existir también una medida de prueba en los casos del Anscheinbeweis -prueba de la apariencia- ${ }^{95}$, es decir, en los supuestos en que claramente la decisión del proceso en favor del actor depende de indicios derivados de una prueba que habitualmente sería considerada insuficiente, pero que en determinados supuestos-tipo frecuentes, puede servir para dar lugar a la demanda ${ }^{96}$. No falta quien intenta cuantificar con guarismos el Beweismaß. ${ }^{97}$

Como se ve, parece que ninguna familia jurídica ha sido ajena al tema de los estándares. Quizás sea por nostalgia de las falsas seguridades que ofrecía el antiguo sistema de la probatio plena/semiplena probatio, o probablemente por darle algún tipo de pauta a los jueces a la hora de cumplir la dificilísima labor de valorar la prueba, una vez superada la vocación de control del secundum allegata et probata, y habiendo asumido ya la confianza que deposita en el juez el sistema de libre valoración de la prueba. Aunque hay que tener en cuenta algunos hechos que son importantes.

En primer lugar, hablar de la probabilidad preponderante y determinarla como una conclusión más probable que improbable, no es ninguna herramienta que ayude al juez, sino que se trata de una simple descripción de su labor cotidiana. Desde luego que para no ser arbitrario, el juez debe declarar probado lo que puede justificar a través de la motivación que le parece más probable, y no lo que le parece menos factible. Es tan obvio que no haría falta ni decirlo.

En segundo lugar, debe tenerse muy presente que la definición de los estándares está sobre todo pensada para el jurado ${ }^{98}$, a fin de ofrecer puntos de referencia que ayuden a construir la

Beweiswürdigung und Beweismaß, Tübingen 2015. BRINKMANN, M., Das Beweismaß im Zivilprozess aus rechtsvergleichender Sicht, Köln 2005.

${ }^{93}$ SCHWEIZER, Beweiswürdigung und Beweismaß, cit. pág. 455.

${ }^{94}$ SCHERER, Inge, Das Beweismaß bei der Glaubhaftmachung, Köln 1996, págs. 4-5 y 75 y sigs.

${ }^{95}$ Me ocupé del concepto en NIEVA FENOLL, “Los sistemas de valoración de la prueba y la carga de la prueba: nociones que precisan revisión”, en La ciencia jurisdiccional: novedad y tradición, Madrid 2016, págs. 268 y sigs, traducido al alemán en NiEVA FENOLL, "Beweislast und Beweiswürdigung: Begriffe, die einer Überprüfung bedürfen”, Zeitschrift für Zivilprozess International, 13, 2008, págs. 297 y sigs.

${ }^{96}$ Vid. Brinkmann, Das Beweismaß im Zivilprozess aus rechtsvergleichender Sicht, cit. págs. 54 y sigs.

${ }^{97}$ Vid. la sorprendente enumeración de autores y porcentajes que reproduce ScHWEIZER, Beweiswürdigung und Beweismaß, cit. pág. 454.

${ }^{98}$ Lo reconocía Wigmore, A Treatise on the System of Evidence in Trials at Common Law, cit. §2497, pág. 3543-3544, citando la opinión del Juez May: "Nevertheless, when anything more than a simple caution and a brief definition is given, the matter tends to become one of mere words, and the actual effect upon the jury, instead of being enlightenment, is rather confusion or, at the least, a continued incomprehension. In practice, these detailed amplifications of the doctrine have usually degenerated into a mere tool for counsel who desire to entrap an unwary judge into forgetfulness of some obscure precedent, or to save a cause for a new trial by quibbling, on appeal, over the verbal propriety of a form of words uttered or declined to be uttered by the judge. "No man can measure with a rule he does not understand; neither can juries determine by rules obscure in themselves and made yet more obscure by attempted definition." The effort to perpetuate and develop these unserviceable definitions is a useless oe, and serves to-day chiefly to aid the purposes of the tactician. It should be wholly abandoned.” 
intuición inmotivada que expresa con su veredicto ${ }^{99}$, habiéndose estudiado la posibilidad de que los jurados quizás podrían verse influidos psicológicamente por las palabras empleadas en cada estándar ${ }^{100}$. Sin embargo, el método es tan inseguro que últimamente hasta se ha llegado a sugerir a los jurados que midan su sensación de sorpresa ante la hipótesis de que el relato de la acusación no fuera cierto ${ }^{101}$, a fin de acreditar la contundencia de su convicción de culpabilidad. En fin, un capítulo más en la historia de una reliquia histórica -el jurado- que por absurdas razones políticas se resiste a morir.

Sea como fuere, los estándares forman parte de la burden of persuasion, es decir, del momento de la decisión, a diferencia de la burden of production, que opera solamente para los jueces en el momento de admitir las pruebas antes de que las vea el jurado, y que tiene por objeto que los jurados presencien solamente material de calidad, y no pruebas falsarias como por ejemplo dictámenes periciales basados en junk science, como recordó la serie de sentencias Daubert ${ }^{102}$. Es importante recordar que en el sistema estadounidense nadie debe motivar el cumplimiento de los estándares, tampoco el juez, por lo que su virtualidad se agota precisamente en ese punto: la convicción inmotivada de los jurados ${ }^{103}$. Quiero decir con ello que no hay nada realmente científico detrás de esos estándares, en el sentido de que no describen la realidad, sino un mero desideratum psicológico que no va a ser comprobado.

De todos modos, aunque sí se procediera a esa comprobación y confirmación a cargo de un juez, el resultado podría ser finalmente el mismo. Pese a que ha habido muy apreciables esfuerzos para dotar de contenido científico a esos estándares ${ }^{104}$, lo cierto es que esos esfuerzos sólo sirven para intentar guiar al juez más en su motivación que en su convicción, en el sentido de que tendrá -teóricamente- que ajustarse al contenido de los estándares a la hora de redactar

\footnotetext{
${ }^{99}$ Vid. DANE, Francis C., “In Search of Reasonable Doubt”, Law and Human Behavior, vol. 9, n. 2, 1985, pág. 142.

${ }^{100}$ Con esta idea se hizo la experimentación de Kagehiro, D. K. / StAnton, C., "Legal vs. Quantified Definitions of Standards of Proof”, Law and Human Behavior, vol. 9, n. 2, 1985, págs. 160 y sigs.

${ }^{101}$ GinTHer, M.; Cheng, E.K., "Surprise vs. Probability as a Metric for Proof", Seton Hall Law Review 48, n. 4, 2018, págs. 1081 y sigs. PARDO, M. S., “Epistemology, psychology, and standards of proof: An essay on Risinger's surprise theory”, Seton Hall Law Review, 48(4), 2018, págs. 1039 y sigs. Vid. también RISINGER, D., "Leveraging surprise: What standards of proof imply that we want from jurors, and what we should say to them to get it”, Seton Hall Law Review, 48(4), 2018, págs. 965 y sigs.

${ }^{102}$ Daubert v. Merrell Dow Pharmaceuticals, 509 U.S. 579 (1993), General Electric Co. v. Joiner, 522 U.S. 136 (1997), Kumho Tire Co. v. Carmichael, 526 U.S. 137 (1999). Sobre esta jurisprudencia, vid. FAIGMAN, David L., "The Daubert Revolution and the Birth of Modernity: Maniging Scientific Evidence in the Age of Science”, Legal Studies Research Paper Series, n. 19, 46 UC Davis Law Review 2013, pág. 104. FouRNIER, Lisa R., “The Daubert Guidelines: Usefulness, Utilization, and Suggestions for Improving Quality Control”, Journal of Applied Research in Memory and Cognition, 5, 2016, pág. 308. GARRIE, Daniel B., “Digital Forensic Evidence in the Courtroom: Understanding Content and Quality", Northwestern Journal of Technology and Intellectual Property, vol. 12, 2014, 2, pág. 122. VÁzQuEZ, Carmen, De la prueba científica a la prueba pericial, Madrid 2015. Dond, Angelo, “Paradigmi processuali ed 'expert witness testimony' nel diritto statunitense”, Rivista Trimestrale di Diritto e Procedura Civile, 1996, págs. 261 y sigs, AulETTA, Ferruccio, Il procedimento di istruzione probatoria mediante consulente tecnico, Padova 2002. ANSANELLI, Vincenzo, La consulenza tecnica nel processo civile, Milano 2011, TARUFFo, Michele, "Prova scientifica e giustizia civile", en AAVV, Giurisprudenza e scienza, Roma 2017, págs. 241 y sigs.

${ }^{103}$ Vid. TARUFFO, "Rethinking the Standards of Proof", cit. pág. 677.

${ }^{104}$ Aparte de la doctrina estadounidense que se está citando, vid. FERrER Beltrán, J., "Prolegomena to a theory on standards of proof. The test case for State liability for wrongful pre-trial detention", inédito 2018, págs. 19 y sigs. FERRER BELTRÁN, J., La valoración racional de la prueba, Madrid 2007.
} 
sus razonamientos ${ }^{105}$. Pero es fácil deducir que por intensos que sean los esfuerzos del juez en esa redacción, al final se van a centrar más en la argumentación de la que sea su decisión, basada en una sensación subjetiva ${ }^{106}$, que en un auténtico ejercicio epistemológico construyendo su convicción de forma gnoseológicamente correcta. Ciertamente, en cualquier cálculo existe una parte subjetiva ${ }^{107}$, pero para ser válido es cálculo, esa subjetividad no puede acabar siendo tan sumamente predominante como en este caso ${ }^{108}$.

Este resultado decepcionante ${ }^{109}$-también para quien escribe- se comprueba no solamente leyendo las motivaciones de demasiados jueces en cuanto a su convicción probatoria, observando cómo seleccionan la información de la práctica de la prueba que les sirve para asentar su conclusión preconcebida, soliendo descartar inmotivadamente el resto. Es que, además, obrar de otra forma sería muy complicado porque es difícil incluir en la motivación de la sentencia absolutamente todos los extremos de un documento o todas las respuestas de la declaración de todos los testigos, explicando por qué le parecen al juez más o menos convincentes.

A lo más a lo que se puede aspirar es a que la motivación del juez sea intersubjetivamente razonable, en el sentido de que pueda convencer a la mayoría de observadores. Y en esa tarea es preciso realizar generalizaciones que desbordan el contenido de los estándares, porque no se puede clasificar a través de los mismos esa convicción judicial de manera que el juez diga que está convencido, más convencido o muy convencido, lo cual, además, no deja de ser una sensación absolutamente subjetiva.

En el fondo, la lógica de los estándares, como vamos a ver enseguida, está basada en la misma lógica matemática ${ }^{110}$ de todo el sistema de valoración legal. Recordemos que se sumaban y se pesaban pruebas, lo que hoy nos parece aberrante, pero entonces era considerado razonable. Es fácil decir que $90^{111}$ es más que 75 y 75 más que 50, pero esa lógica aritmética no se puede hacer realidad en un sistema de libre convicción judicial ${ }^{112}$, salvo que se pueda medir científicamente

\footnotetext{
${ }^{105}$ Cfr. GASCÓn ABELLÁn, M., “Sobre la posibilidad de formular estándares de prueba objetivos”, DOXA, Cuadernos de Filosofía del Derecho, 28, 2005, pág. 137.

${ }^{106}$ RosenberG, Leo / SchwAB, Karl Heinz / GotTwALD, Peter, Zivilprozessrecht, cit. pág. 686.

${ }^{107}$ Vid. LoEvinger, L., “Standards of Proof in Science and Law”, Jurimetrics Journal, 32, n. 3, págs. 328, 335.

${ }^{108}$ Vid. la ilustrativa conclusión de Clermont, K. M., "Standards of Proof Revisited”, Cornell Law Faculty Publications, 13, 2009, págs. 487: “The psychological mechanism for implementing standards of proof remains to be discovered. For the time being, science gives law no reason to abandon its traditional hope that its intuitive fact-finder roughly estimates the subjective probability of the burdened party's version of fact, and then compares the probability to a set scale of coarse gradations of probability, such as asking whether the version appears more likely than not or whether the version appears almost certain."

${ }^{109}$ Cfr. BALL, V.C., "The Moment of the Truth: Probability Theory and Standards of Proof”, 14 Vanderbilt Law Revies, vol. 14, 1961, pág. 830.

${ }^{110}$ Vid. DeKay, M.L., "The difference between Blackstone-Like Error Ratios and Probabilistic Standards of Proof, Law and Social Inquiry, 21, n. 1, 1996, pág. 97.

${ }^{111}$ Es el porcentaje que suele citarse como referencia del beyond any reasonable doubt. Vid. VARs, F. E., “Toward general theory of standards of proof”, Catholic University Law Review, 60 (1), 2010, pág. 2.

${ }^{112}$ Aunque algunos sugieren la interesante conclusión de que una referencia numérica puede orientar eficazmente a los jurados. Magnussen, S. / Eilertsen, D.E. / Teigen, K.H. / Wessel, E., "The Probability of Guilt in Criminal Cases: Are People Aware of Being 'Beyond Reasonable Doubt'?”, Applied Cognitive Psychology, 28, 2014, págs. 196 y sigs.
} 
la intensidad cerebral de la convicción humana, cosa que hoy no es posible ${ }^{113}$, y ni siquiera puede decirse que fuera útil ${ }^{114}$.

Lo que intento decir se observa con la apreciación del probablemente único estándar probatorio utilizado en España con cierta conciencia de que lo es: la prueba prima facie ${ }^{115}$. Se trata de una convicción superficial, rápida aunque no precipitada, que concede una tutela -habitualmente cautelar- a alguien que todavía tiene que demostrarla en un proceso. $\mathrm{O}$ que sirve para admitir a trámite una denuncia o querella, o una declinatoria o una tercería de dominio, al considerar mínimamente creíble la historia que cuenta el solicitante. En realidad, esa formulación es muy probable que sea una simple secuela de la antigua semiplena probatio.

Pero si nos acercamos al lado práctico de esos enjuiciamientos nos daremos cuenta de que en su mayoría exigen una convicción judicial total, al menos con los datos que en ese momento están sobre la mesa, que salvo en el caso de la denuncia -y no siempre-suelen ser todos los datos que se aportarán también en el proceso. Quizás es más exacto decir que el juez, para tomar cualquier decisión, debe tener una convicción que pueda motivar razonablemente con los datos de que disponga en cada momento. Intentar medir el nivel de convicción judicial es simplemente imposible. Es una sensación tan subjetiva como los intentos de objetivar el contenido de cada estándar ${ }^{116}$. En realidad, cuando se intenta esa objetivación se cae en la misma subjetividad al contener dicha objetivación elementos valorativos difícilmente justificables hasta las últimas consecuencias ${ }^{117}$.

En suma, como antes se dijo, bien parece que en este contexto se esté expresando una añoranza por las seguridades del pasado de la prueba legal. Esas seguridades pueden obtenerse a veces, cuando todo el material probatorio es unívoco. Pero si no lo es -y a veces no lo es-, inevitablemente se entra en el subjetivismo para intentar -no nos engañemos- adivinar lo que ocurrió. Y justamente ahí es cuando olvidamos la afirmación de uno de los pocos juristas que, a mi juicio, sin llevar la cuestión al cumplimiento de ningún estándar, centró el tema de manera más correcta y útil.

Me estoy refiriendo a ULPIANO y su referencia a las sospechas.

"Pero Trajano respondió por rescripto a Adsiduo Severo que nadie debía ser condenado por sospechas: es preferible que se deje impune el delito de un culpable antes que condenar a un inocente." 118

No es controvertido lo que es una sospecha. Es lo contrario de una certeza, es decir, una incertidumbre. Lo que dijo el jurista romano es bien fácil de entender, aunque suene duro a los punitivistas. Es preferible que se escapen delincuentes a que condenemos a un inocente. Si no

\footnotetext{
${ }^{113}$ PEČARIČ, M. / KOZJEK, T., "From rational to more rational standards of proof”, International Journal of Public Policy, Enero 2016, págs. 115 y sigs.

${ }^{114}$ CleRmont, K.M., “Staying Faithful to the Standards of Proof”, cit. pág. 3.

${ }^{115}$ Sobre el concepto, NiEVA FENOLL, J., Enjuiciamiento prima facie, Barcelona 2007.

${ }^{116}$ FerRer Beltrán, "Prolegomena to a theory on standards of proof. The test case for State liability for wrongful pre-trial detention”, inédito 2018, págs. 19 y sigs.

${ }^{117}$ GonZÁlez LAgIER, "Prueba y argumentación. ¿Es posible formular un estándar de prueba preciso y objetivo? Algunas dudas desde un enfoque argumentativo de la prueba”, inédito 2018, pág. 13.

${ }^{118}$ Dig. L. 48, tít. 19, 5. Ulpiano: "sed nec de suspicionibus debere aliquem damnari divus traianus adsidio severo rescripsit: satius enim esse impunitum relinqui facinus nocentis quam innocentem damnari.”
} 
podemos afirmar tajantemente que alguien ha cometido un delito, debemos absolverlo. Y por supuesto, podríamos decir que UlPIANo - pese a la época a la que pertenece- era un "inocentista" y por tanto un exagerado, y que lo correcto es condenar cuando existen datos probatorios que involucran a un sujeto con el crimen, pero también datos en sentido contrario igualmente fiables. Pero seguimos respetando la máxima de UlPIANO, es decir, la presunción de inocencia, porque nos sigue pareciendo -ojalá que por mucho tiempo ${ }^{119}$ - lo más justo.

Por ello creo que ha sido más certera la estrategia de la probabilidad inductiva ${ }^{120}$ tanto en su método como en sus resultados, compatibles además con las orientaciones de la psicología ${ }^{121}$ sobre el particular y hasta con algunos desarrollos doctrinales sobre los estándares de prueba. La idea consiste en trazar hipótesis bien construidas que expliquen un relato de hechos relevante para el proceso. Sólo si logramos descartar razonablemente todas las hipótesis alternativas a la del relato de culpabilidad, podremos condenar, y siempre que este relato sea también razonable. Eso es justo lo que reclamaba UlPIANO. Pero intentar elevar este acertado modus operandi o estrategia a la categoría de estándar me parece desacertado, porque no es posible explicarlo con el detalle que precisa la seguridad que debiera dar un estándar.

Bien al contrario, tanto a un juez como -muy especialmente- a un jurado, sería mucho más útil decirles que deben elaborar hipótesis diferentes sobre cómo sucedieron los hechos, procediendo al descarte de las que no les parezcan razonables. Si ninguna les parece razonable, deben absolver, aunque no hayan logrado configurar un relato. Sólo si una hipótesis inculpatoria parece razonable y se pueden descartar, no por intuición, sino con argumentos, las hipótesis de inocencia, se podrá condenar legítimamente. No hay que dejarse llevar por la rabia contra alguien que prejuzgamos como delincuente y que nos produce coraje que pueda escaparse. Esa debería ser la segunda advertencia, insisto que tanto a jueces como a jurados, allí donde todavía existan.

Y lo mismo debe ocurrir en un proceso civil, aunque sin la referencia de la presunción de inocencia, lo que, por cierto, hace las cosas más complicadas. En un proceso civil aparecerán varias hipótesis de lo que es razonable. El juez debe escoger la que pueda fundamentar mejor, sin deber preferir por defecto la opción que beneficia a una de las partes. En el proceso penal sí debe existir esa preferencia para compensar la desigualdad que en el proceso le produce al reo el enorme poder investigador del Estado - particularmente de la policía- que puede convertir muy fácilmente a un inocente en culpable. Y además para combatir el enorme prejuicio social de culpabilidad que padece toda la población humana, y que es la principal razón de existencia de la presunción de inocencia ${ }^{122}$.

En consecuencia, en mi opinión es conveniente huir de la lógica de los estándares de prueba. Fueron pensados, primero, para controlar a los jueces, y más adelante para orientar a jurados

\footnotetext{
${ }^{119}$ Aunque existen ya voces que empiezan a pronunciarse parcialmente en contra, sugiriendo emplear un estándar de prueba más bajo para los reos reincidentes, lo que puede esconder una intención de orillar finalmente la presunción de inocencia. Vid. LAUDAN, Larry, "Different Strokes for Different Folks: Fixing the Error Pattern in Criminal Prosecutions by Empiricizing the Rules of Criminal Law and Taking False Acquittals and Serial Offenders Seriously", Seton Hall Law Review 48, n. 4, 2018, págs. 1243 y sigs.

${ }^{120}$ Conen, Lawrence Jonathan, The probable and the provable, Oxford 1977, págs. 121 y sigs.

${ }^{121}$ Johnson-Laird, pág. N., "Mental Models and Probabilistic Thinking”, Cognition, 1994, 50, págs. 191 y sigs.

${ }^{122}$ Nieva Fenoll, La duda en el proceso penal, Madrid 2013, págs. 75 y sigs.
} 
sobre todo. Pero ni aquellos lograron una mejor justicia, ni estos han logrado poseer el empirismo necesario para ser considerados realmente científicos, más allá de una posible virtualidad en la orientación del comportamiento de un juez ${ }^{123}$. Bien al contrario, es mejor enfrentarse con la realidad y sus múltiples caras tal y como es, seleccionando la que el juez pueda justificar que es más razonable. Poco más -y no es poco- puede hacerse.

\section{Las razones del sistema de prueba legal.}

Se han dicho ya algunas de las razones del sistema de prueba legal y se ha explicado sumariamente cómo funcionaba este absurdo escenario probatorio. Pero conviene profundizar en esas razones del sistema, que ciertamente las tenía.

Aunque no se ha dicho habitualmente de ese modo, cuando se repasan las resistencias doctrinales que durante el siglo XIX se sucedieron para suprimir el sistema de prueba legal ${ }^{124}$, sobre todo en el proceso civil, se descubren claramente cuáles fueron esas razones de por qué la doctrina concibió un sistema en el que el juez o pudiera introducir hechos en el proceso, no pudiera ser proactivo con las alegaciones de las partes y no pudiera valorar la prueba a su voluntad.

En el siglo XIX temían los abogados que los procesos se les fueran de las manos. Lo siguen temiendo aún hoy muchos cada vez que oyen hablar de prueba de oficio. Pues bien, ese terror en el siglo XII estaba perfectamente justificado en la época ${ }^{125}$. Los jueces eran simples delegados del poder político. Por tanto, carecían de independencia y además adolecían de una preparación muy precaria, básicamente la que cabe suponer en un jurista antes del nacimiento de las Universidades, y sobre todo en alguien que es designado por el poder político, lo que hace pensar en él como un "amigo" o protegido, es decir, un inepto. En alguien así no podían confiar los primeros juristas universitarios de la historia, y mucho menos para encomendarles las controversias comerciales propias de su nivel estamental, que no era el de la nobleza o realeza que había designado al juez.

Por tanto, diseñaron un sistema en el que el juez tiene que trabajar lo menos posible. No puede utilizar su intuición o consciencia ni tampoco su conocimiento privado de los hechos, sino que solamente podía juzgar secundum allegata et probata (partium). Así nació el principio dispositivo ${ }^{126}$, del que mucho después emanó el principio de aportación de parte (Verhandlungsmaxime) $^{127}$. No se le permitió tampoco ir ultra petta partium. En el fondo, se trata de una expresión medieval del derecho de defensa. En ese contexto las partes podían atacarse y

\footnotetext{
${ }^{123}$ Demougin, D. / Fluet, C., Deterrence vs. Judicial Error: A Comparative View of Standards of Proof, Journal of Institutional and Theoretical Economics, 161, 2005, págs. 193 y sigs.

${ }^{124}$ Vid. GneIst, Rudolph, Die Bildung der Geschworenengerichte in Deutschland, Berlin 1849,pág. 62. BÄHR, Otto, Die Grenzen der freien Beweistheorie, en: Jahrbücher für die Dogmatik des heutigen römischen und deutschen Privatrechts, T. 25 (1887),pág. 413. Heusler, Andreas, Die Grundlagen des Beweisrechts, AcP nº 62 (1879), pág. 305.

${ }^{125}$ Lo explico en Nieva FenolL, “La actuación de oficio del juez nacional europeo”, cit.

${ }^{126}$ JAUERnig / Hess, Zivilprozessrecht, cit.pág. 93. RosenBERG, Leo / SchwAB, Karl Heinz / GotTwaLD, Peter, Zivilprozeßrecht, cit. págs. 425 y sigs. SERRA DOMÍNGUEZ, Manuel, Liberalización y socialización del proceso civil, RDProc, 1972, pág. 520. ETXEBERRIA GuRIDI, José Francisco, Las facultades judiciales en materia probatoria en la LEC, Valencia 2003, págs. 31 y sigs.

${ }^{127}$ JAUERNIG / HESs, Zivilprozessrecht, cit.pág. 97.
} 
defenderse sin que el juez interfiriera o se decantara por una u otra. Y así consiguieron, además de garantizar el derecho de defensa, a un juez independiente e imparcial.

Pero aunque el juez no interfiriera en lo que alegaban y aportaban como prueba las partes, siempre podía escapar del control de los litigantes sobre el objeto del juicio valorando la prueba libremente. Justamente esto último es lo que impidió el sistema de prueba legal. Sólo se daría por probado lo que dijera la ley, a través de la plena probatio. Todo el resto sería una prueba mperfecta, es decir, la semiplena probatio, que sí que era claramente susceptible de valoración libre, aunque en general los jueces se limitaban a "pesar" dicha prueba ${ }^{128}$.

Sin embargo, entonces entró en juego otro factor que aún se observa en algunos lugares en los que se conserva la prueba legal, y que de hecho explica las decisiones de no pocos servidores públicos y a veces también privados: la minimización de la carga cognitiva ${ }^{129}$, o ley del mínimo esfuerzo. Dicha "ley" dicta que ante una perspectiva de decisión, el ser humano tiene la tendencia a adoptar la que le cuesta menor esfuerzo cognitivo. Pues bien, el sistema legal era un sistema realmente fácil de aplicar en la práctica. Solamente había que sumar testigos, tomar juramentos y comprobar que un documento es público. No es de extrañar que este sistema provocara el absentismo de los jueces, porque no hacían la más mínima falta. En realidad, el juez pasó a ser lo que es ahora todavía en demasiadas latitudes. Un sujeto cargado de un halo de autoridad que simplemente firma el trabajo mecánico que hace el personal de su juzgado.

No es nada extraño que varios autores quisieran que el sistema cambiara para que los jueces, por su propio sentido común, acreditaran la realidad al margen de las injusticias de las pruebas legales. El mismo VolTAIRE ${ }^{130}$ fue uno de los más destacados en contra del sistema y que, por tanto, puso las bases del cambio.

\section{Las razones del sistema de libre valoración de la prueba.}

Bentham fue probablemente el que hirió de muerte el sistema de prueba legal ${ }^{131}$. La justificación era muy sencilla: es un sistema contrario a la lógica, sin más. No podía ser que en un caso concreto todo el mundo viera racionalmente una determinada realidad, y en cambio la justicia se separara de la realidad por culpa del sistema de valoración legal. Es probable que la incomprensión social por las decisiones de los jueces venga de entonces, momento en el que sin duda se creó la idea de que una cosa era la verdad y otra lo que declaraban los jueces. Los conceptos de verdad formal y verdad material, que describían muy gráficamente el antiguo y el

\footnotetext{
${ }^{128}$ De nuevo, Jaumar y CARrera, Práctica forense, cit.pág. 48.

${ }^{129}$ GARnHAM, Alan / OAKHILL, Jane, Manual de psicología del pensamiento, trad. de Eva JuARros DausSÁ de la obra Thinking and reasoning de 1994, Barcelona 1996, pág. 288.

${ }^{130}$ Voltaire, (François-Marie Arouet), Oeuvres complètes de Voltaire, t. XXXVI, Politique et législation, vol. 4, Bruselas 1829, págs. 104 y sigs

${ }^{131}$ Bentham, Traité, cit. pág. 9. “...on remonte à l'origine de ces règles si gênantes et si peu raisonnables, de cette variété de tribunaux qui ont chacun leur système et qui multiplient si étrangement les questions de compétence, de ces fictions puériles qui mêlent sans cesse l'œuvre du mensonge à la recherche de la vérité. L'histoire de cette jurisprudence est le contraire de celle des autres sciences : dans les sciences, on va toujours en simplifiant les procédés de ses prédécesseurs ; dans la jurisprudence, on va toujours en les compliquant davantage. Les arts se perfectionnent en produisant plus d'effets par des moyens plus faciles ; la jurisprudence s'est détériorée en multipliant les moyens et en diminuant les effets.”
} 
nuevo sistema respectivamente, trataron justamente de desautorizar al sistema legal ${ }^{132}$, aunque luego fueran tal mal entendidos.

Por tanto, lo que correspondía era desmontar el sistema. Si se renuncia a la valoración legal, automáticamente debe caer también la idea de que las partes deben aportar al proceso la prueba que les favorezca, por lo que se abre paso el principio de adquisición procesal y deja de tener sentido la carga subjetiva de la prueba. Y si, como hemos visto, la carga objetiva al final se centra en una cuestión de pura valoración racional, el concepto de carga objetiva decae también. Se supera así la noción de carga de la prueba por completo.

Incluso se empieza a apuntar el paso siguiente, que consiste en acabar de desmontar el secundum allegata et probata abriendo la puerta a la prueba de oficio, atribuyendo una confianza al juez que no tuvo en el pasado. Todos los pasos citados fueron o son polémicos, pero este último en concreto ha despertado unas inquinas doctrinales impropias ${ }^{133}$ que han oscurecido la intención de fondo: que el sistema de valoración libre pueda desplegar todos sus efectos.

En Derecho siempre es muy costoso y arriesgado luchar contra la tradición, pero es obligado hacerlo si sigue parámetros absurdos. El problema es que cuando se desmonta un sistema hay que construir una alternativa razonable, y ahí fallaron todos los tratadistas del siglo XIX y buena parte del XX. Probablemente tenían tanta confianza en el Imperio de la Razón que pensaron que se impondría por sí sola. No fue así. Los jueces fueron utilizando las expresiones "íntima convicción", "sana crítica” o "máximas de la experiencia” simplemente para encubrir con una frase hermosa el uso de su propia intuición. Hay que reconocer que se les había dejado a los pies de los caballos. Del cómodo sistema de valoración legal pasaron de repente a la nada. Y encima se les exigía que motivaran.

Los intentos de orientarles realmente tardaron aún mucho tiempo. Los estándares probatorios, pura reminiscencia mimética del sistema legal, no sirvieron de mucho, pero al menos pusieron el objetivo en el lugar adecuado, el razonamiento judicial, convirtiendo el problema en una cuestión epistemológica, lo que es acertado y propició trabajos de procesalistas con profunda formación filosófica como Michele TARUFFO ${ }^{134}$, o directamente de filósofos del Derecho ${ }^{135}$. Ellos

\footnotetext{
${ }^{132}$ Busch, Der zwiespalt der deutschen Gesetzgebungen, cit.pág. 65. ENDEMANN, Wilhelm, Die Folgen freier Beweisprüfung im Civilprozesse, AcP nº 41(1858),pág. 324.

${ }^{133}$ Endemann, Die Folgen freier Beweisprüfung im Civilprozesse, cit. págs. 289 y sigs. WACH, Adolf, Der Entwurf einer deutschen Civilprozeßordnung, Kritische Vierteljahresschrift für Gesetzgebung und Rechtswissenschaft vol. 14 1872, págs. 331 y sigs. Von Canstein, Raban Freiherr, Die Grundlagen des Beweisrechts, ZZP no 2 (1880),pág. 351. CAVAllone, Bruno, En defensa de la verifobia, en: "CAVAlLONE / TARUfFo, Verifobia, un diálogo sobre prueba y verdad, Lima 2010, pág. 31. MonTERo ArocA, Juan (con Gómez Colomer y Barona Vilar), Derecho jurisdiccional, I, Valencia 2012, pág. 266. Alvarado Velloso, Adolfo, La prueba judicial, Valencia 2006, pág. 25. CIPRIANI, El proceso civil entre viejas ideologías y nuevos eslóganes, in Montero Aroca (coord.), Proceso civil e ideología. Un prefacio, una sentencia, dos cartas y quince ensayos, Valencia, 2006, pág. 93.

${ }^{134}$ Entre otros muchos trabajos, TARUFFO, Michele, La motivazione della sentenza civile, Padova 1970. TARUfFo, Michele, La prueba de los hechos, trad. de Jordi Ferrer Beltrán de "la prova dei fatti giuridici, milano 1992, Madrid 2002.

${ }^{135}$ Por todos, LAUDAN, L., Truth, error and criminal law: an essay in legal epistemology, New York 2006. HAACK, S., Evidence Matters, New York 2014. Gascón AbelLÁn, M., Los hechos en el Derecho. Bases argumentales de la prueba, Madrid 2004. FERRER BELTRÁN, J., La valoración racional de la prueba, Madrid 2007. FERRER BELTRÁN, Jordi, Prueba y verdad en el derecho, Madrid 2005.
} 
han ayudado a centrar el problema en su justa dimensión y han puesto encima de la mesa las carencias estructurales del sistema.

Esas carencias son el problema actual de la valoración libre. Empieza a estar asumido el reconocimiento de que para valorar la prueba hay que salir del Derecho y mirar a la ciencia ${ }^{136}$. De ahí que la psicología del testimonio ${ }^{137}$ haya supuesto una herramienta esencial en las pruebas de interrogatorio, o que la semiótica textual nos esté ayudando a interpretar debidamente los documentos, más allá de su lectura.

Habiendo avanzado muchísimo en materia de razonamiento probatorio con resultados bien tangibles, a mi juicio ${ }^{138}$, el problema actual más acuciante de la valoración de la prueba se centra en la prueba pericial. Le pedimos a un no experto -el juez- que valore la labor de un experto: el perito. Es más o menos lo mismo que pedirle a un biólogo que valore una sentencia sobre cosa juzgada. Daubert nos ha ayudado a poner sobre las vías de la racionalidad este auténtico disparate, pero aún falta mucho por hacer.

En todo caso, hemos llegado al imperio de la libre valoración de la prueba, lo que obliga a liberarse de todas las ataduras del pasado: estándares probatorios, carga de la prueba y una visión demasiado estricta del principio de aportación de parte. Queda para el futuro el resultado procesal que ello provocará, que se verá afectado además por otros factores relevantes, entre ellos el tecnológico ${ }^{139}$. En todo caso, especialmente con este último habrá que estar muy pendiente de no perder la racionalidad a cambio de cálculos estadísticos sesgados y oscurantistas. El imperio de la razón fue una conquista social. Merecería la pena no perderlo.

\section{Bibliografía.}

ACCURSIUS, e.a. (1604), Corporis Iustinianaei Digestum Vetus, seu Pandectarum, Vol. 6, Lyon, pág. 17.

Tomás-Javier Aliste SANTOS (2011), La motivación de las resoluciones judiciales, Marcial Pons, Madrid.

Tomás-Javier Aliste SANTOS (2010), "Relevancia del concepto canónico de "certeza moral" para la motivacion judicial de la "quaestio facti" en el proceso civil", Ius ecclesiae, Vol. 22, n. 3, págs. 651 y sigs.

Adolfo AlVARAdo Velloso (2006), La prueba judicial, Tirant lo Blanch, Valencia.

Vincenzo ANSANELLI (2011), La consulenza tecnica nel processo civile, Giuffrè, Milano.

Ferrucio AUlETTA (2002), Il procedimento di istruzione probatoria mediante consulente tecnico, CEDAM Padova.

\footnotetext{
${ }^{136}$ Es el enfoque que seguí en NiEva FenolL, La valoración de la prueba, Madrid 2010.

${ }^{137}$ Por todos, Manzanero, A. L., Psicología del testimonio, Madrid 2008.

${ }^{138}$ NieVA Fenoll, "Repensando Daubert: la paradoja de la prueba pericial”, en AAVV, Peritaje y prueba pericial, Barcelona 2017, págs. 85 y sigs.

${ }^{139}$ NiEVA FenOLL, Inteligencia artificial y proceso judicial, Madrid 2018, págs. 79 y sigs.
} 
Azzone (o Azo o Azón) (1567), Brocardica (aurea). sive generalia iuris, Basilea, rúbrica XX, pág. 23.

Azzone (1581), Summa Azonis, Venecia, lib. III.

Otto BÄHR (1887), Otto, „Die Grenzen der freien Beweistheorie“, Jahrbücher für die Dogmatik des heutigen römischen und deutschen Privatrechts, T. 25, págs. 413 y sigs.

V.C. BALL (1961), "The Moment of the Truth: Probability Theory and Standards of Proof”, 14 Vanderbilt Law Review, vol. 14, págs. 830 y sigs.

L. BAR (1867), Recht und Beweis im Zivilprozesse, Leipzig, págs. 46 y sigs.

Rolf BENDER / Armin NACK, / Wolf-Dieter TREUER (2007), Tatsachenfeststellung vor Gericht, C.H. Beck, München 2007.

Rolf BENDER /Armin NACK (1980), „Grundzüge einer Allgemeinen Beweislehre“, Deutsche Richterzeitung, págs. 121 y sigs.

Jérémie Bentham (1823), Traité des preuves judiciaires, Paris, t. II.

Chiara BeSSo-MARCheIS (2015), "La vicinanza della prova", Revista Eletrônica de Direito Procesual, v. 16, págs. 93 y sigs. En: http://www.epublicacoes.uerj.br/index.php/redp/article/view/19962/14303.

F. BeX / D. WaLton (2012), "Burdens and standards of proof for inference to the best explanation: three case studies”, Law, Probability and Risk 11, págs. 118 y sigs.

William Blackstone (1776), Commentaires sur les loix angloises, traduits de l'Anglois par Auguste-Pierre Damiens de Gomicourt sur la quatrieme edition d'Oxford, t. V, Bruselas.

William BLACKSTONE (1794), Commentaries on the Laws of England, III, London.

M. BRinKmann (2005), Das Beweismaß im Zivilprozess aus rechtsvergleichender Sicht, Carl Heymanns, Köln.

Bruno CAVAllone (2010), "En defensa de la verifobia”, en CAVALLONE / TARUfFo, Verifobia, un diálogo sobre prueba y verdad, Palestra, Lima, págs. 31 y sigs.

Franco CIPRIANI, “El proceso civil entre viejas ideologías y nuevos eslóganes”, en MonTERo AROCA (coord.), Proceso civil e ideología. Un prefacio, una sentencia, dos cartas y quince ensayos, Tirant lo Blanch, Valencia, 2006, págs. 93 y sigs.

K.M. Clenmont (2009), “Standards of Proof Revisited”, Cornell Law Faculty Publications, 13, págs. 469 y sigs.

K.M. Clermont / E. Sherwin (2002), "A Comparative View of Standards of Proof”, American Journal of Comparative Law 50, n. 2, primavera, págs. 243 y sigs. 
K.M. Clermont, (2018), "Staying Faithful to the Standards of Proof", Cornell Legal Studies Research Paper, n. 18-45, págs. 2 y sigs.

Lawrence Jonathan COHEN (1977), The probable and the provable, Oxford University Press, Oxford.

Giuseppe ChIovenda (1923), Principi di Diritto Processuale, $3^{\text {a }}$ ed. Napoli.

Andrew L-T CHOO, (2009), Evidence, Oxford University Press, Oxford.

Elena D’ALESSANDRO (2018), “Onere della prova e legge applicabile”, Giurisprudenza italiana, Nov., págs. 2546 y sigs.

Gaspare DALIA (2018), Convincimento giudiziale e ragionevole dubbio, CEDAM, Milano.

Francis C. DANE (1985), "In Search of Reasonable Doubt”, Law and Human Behavior, vol. 9, n. 2, págs. 142 y sigs.

Martino DE FANO (1584), “Negativa qualiter probanda”, en: "AAVV, Tractatus illustrium in utraque tum Pontificii, tum Caesarei iuris facultate Iurisconsultorum, De Probationibus, T. IV, Venecia, pág. 12, n. 3 ("Probandi facilitas transmittit onus probationis. Legitimatio personae standi in iudicio per quem probanda").

Bertrand DE LA TOUR (1776), Oeuvres, Colonia.

José DE Vicente y CARAVANTES (1856), Tratado histórico, crítico filosófico de los procedimientos judiciales en materia civil según la nueva Ley de Enjuiciamiento, Madrid.

M.L. DeKAY (1996), “The difference between Blackstone-Like Error Ratios and Probabilistic Standards of Proof”, Law and Social Inquiry, 21, n. 1, págs. 97 y sigs.

D. Demougin / C. Fluet (2005), "Deterrence vs. Judicial Error: A Comparative View of Standards of Proof”, Journal of Institutional and Theoretical Economics, 161, págs. 193 y sigs.

DENNIS (2013), The Law of Evidence, Sweet \& Maxwell, London.

Jonathan DoAK / Claire Mcgourlay (2009), Criminal evidence in context, Routledge-Cavendish, London - New York.

Angelo Dondi (1996), "Paradigmi processuali ed 'expert witness testimony' nel diritto statunitense”, Rivista Trimestrale di Diritto e Procedura Civile, págs. 261 y sigs.

Guilielmus DuRANTIS (1602), Speculum iuris, Venecia, lib. I.

Wilhelm EndEMANN (1858), „Die Folgen freier Beweisprüfung im Civilprozesse“, AcP $\mathrm{n}^{\mathrm{o}}$ 41(1858), págs. 324 y sigs. 
Ramon EsCALER BASCOMPTE (2017), La carga de la prueba, Atelier, Barcelona.

José Francisco ETXEBERRIA GURIDI (2003), Las facultades judiciales en materia probatoria en la Ley de Enjuiciamiento Civil, Tirant lo Blanch, Valencia 2003.

David L. Faigman (2013), “The Daubert Revolution and the Birth of Modernity: Maniging Scientific Evidence in the Age of Science”, Legal Studies Research Paper Series, n. 19, 46 UC Davis Law Review, pág. 104.

Jordi FERRER BELTRÁN (2018), "Prolegomena to a theory on standards of proof. The test case for State liability for wrongful pre-trial detention”, inédito, págs. 19 y sigs.

Jordi FERRER BELTRÁN (2007), La valoración racional de la prueba, Marcial Pons, Madrid.

Jordi FerRer Beltrán (2005), Prueba y verdad en el derecho, Marcial Pons, Madrid.

Lisa R. FOURNIER (2016), “The Daubert Guidelines: Usefulness, Utilization, and Suggestions for Improving Quality Control”, Journal of Applied Research in Memory and Cognition, 5, págs. 308 y sigs.

Alan GARNHAM / Jane OAKHILl (1996), Manual de psicología del pensamiento, trad. de Eva Juarros Daussá de la obra Thinking and reasoning de 1994, GBS Grupo Planeta, Barcelona.

B. GARNOT (2010), "Voltaire et la justice d'ancien régime: la médiatisation d'une imposture intellectuelle”, Nouveau Monde Éditions, n. 15, pág. 29.

Daniel B. GARRIE (2014), "Digital Forensic Evidence in the Courtroom: Understanding Content and Quality”, Northwestern Journal of Technology and Intellectual Property, vol. 12, 2014, 2, págs. 122 y sigs.

Marina GASCÓN ABELLÁN (2005), "Sobre la posibilidad de formular estándares de prueba objetivos”, DOXA, Cuadernos de Filosofía del Derecho, 28, págs. 137 y sigs.

Marina GASCón ABELLÁN (2004), Los hechos en el Derecho. Bases argumentales de la prueba, Marcial Pons, Madrid.

M. GinTHER / E.K. CHENG (2018), "Surprise vs. Probability as a Metric for Proof”, Seton Hall Law Review 48 , n. 4, págs. 1081 y sigs.

Julius GLASER (1883), Handbuch des Strafprozesses, vol. I, 1883.

Rudolph GNEIST (1849), Die Bildung der Geschworenengerichte in Deutschland, Berlin.

Daniel GonZÁlez LAGIER (2020), "Prueba y argumentación. ¿Es posible formular un estándar de prueba preciso y objetivo? Algunas dudas desde un enfoque argumentativo de la prueba”, Revista Telemática de Filosofía del Derecho, n. 23, págs. 91 y ss. 
Thomas F. GORDON / Douglas WALTON (2011), "A formal model of legal proof standards and burdens”, en EMEREN, F.H. van (Ed.); GARSSEN, B. (Ed.); GodDEN, D. (Ed.); MeufFels, B. (Ed.); International Society for the Study of Argumentation -ISSA-:7th Conference of the International Society for the Study of Argumentation 2010. Proceedings: Amsterdam, June 29 to July 2, 2010, Sic Sac, Amsterdam, págs. 644 y sigs.

Peter GotTwaLD (2000), „Das relative Beweismaß im englischen und deutschen Zivilprozeß“, FS Henrich, págs. 165 y sigs.

Ulrike GRÄFE (2011), Leo Rosenberg - Leben und Wirken (1879-1963), Duncker \& Humblot, Berlin, págs. 46 y sigs.

Wolfgang GRUNSKY (2003), Zivilprozessrecht, Luchterhand, Bielefeld.

A. Guerra / B. LuPPI / F. PARISI (2019), "Standards of Proof and Civil Litigation: A GameTheoretic Analysis”, The B.e. Journal of Thworetical Economics, págs. 2 y sigs.

Susan HAACK (2014), Evidence Matters, Cambridge, New York.

Andreas HeuSLER (1879), „Die Grundlagen des Beweisrechts“, $A c P$ nº 62, págs. 305 y sigs.

Othmar JAUERNIG / Burkhard HESS (2011), Zivilprozessrecht, C.H. Beck, München.

Joaquín JAUMAR y CARRERA (1840), Práctica forense, Barcelona.

Philip N. Johnson-LAIRD (1994), "Mental Models and Probabilistic Thinking”, Cognition, 50, págs. $191 \mathrm{y}$ sigs.

D.K. Kagehiro / C. Stanton (1985), "Legal vs. Quantified Definitions of Standards of Proof", Law and Human Behavior, vol. 9, n. 2, págs. 160 y sigs.

Max KASER / Karl HACK (1996), Das römische Zivilprozessrecht, C.H. Beck, München.

Adrian KeANE (2000), The modern law of evidence, Butterworths, Oxford.

Josef KOHLER (con HOLTZENDORFF) (1904), Encyclopädie der Rechtswissenschaft, vol. 3, Leipzig, págs. 315 y sigs.

Federico LaRa Peinado (1997), Código de Hammurabi, Tecnos. Madrid.

Larry LAUDAN (2006), Truth, error and criminal law: an essay in legal epistemology, Cambridge University Press, New York.

Larry LAUDAN (2018), “Different Strokes for Different Folks: Fixing the Error Pattern in Criminal Prosecutions by Empiricizing the Rules of Criminal Law and Taking False Acquittals and Serial Offenders Seriously”, Seton Hall Law Review 48, n. 4, págs. 1243 y sigs. 
Hans-Willi LAUMEN (2009), „Grundbegriffe der Beweislast“, en BAUMGäRTEL / LAUMEN / PRÜTTING, Handbuch der Beweislast, Heymanns, München, págs. 42 y sigs.

Dieter LeIPOLD (1985), Beweismaß und Beweislast im Zivilprozeß, De Gruyter, Berlin.

Dieter LeIPOLD (1997), Comentario al \$286 ZPO, en STEIN/JONAS, Kommentar zur ZPO, Mohr Siebeck, Tübingen, págs. 527 y sigs.

Carlo Lessona (1928), Teoría general de la prueba en Derecho Civil, Parte General, Trad. de Enrique Aguilera de Paz, Madrid.

L. LOEVINGER (1992), "Standards of Proof in Science and Law”, Jurimetrics Journal, 32, n. 3, págs. 328 y sigs.

Wolfgang LÜKE (2011), Zivilprozessrecht, C.H. Beck, München.

Joaquín LLOBELL TUSET (1998), “La certezza morale nel processo canonico matrimoniale”, en Il Diritto Ecclesiástico, 109/1, págs. 771 y sigs.

S. Magnussen / D.E. Eilertsen / K.H. Teigen / E. Wessel (2014), "The Probability of Guilt in Criminal Cases: Are People Aware of Being 'Beyond Reasonable Doubt'?”, Applied Cognitive Psychology, 28, págs. 196 y sigs.

Antonio L. MAnZANero Puebla (2008), Psicología del testimonio, Pirámide, Madrid.

Gian Antonio MicheLI (1966), L’onere della prova, CEDAM, Padova 1966.

Manuel MiRANDA EstRAMPeS (2019), Prueba ilícita y regla de exclusión en el sistema estadounidense. Crónica de una muerte anunciada, Marcial Pons, Madrid.

Juan Montero Aroca (2012), (con Gómez Colomer y Barona Vilar), Derecho jurisdiccional, I, Tirant lo Blanch, Valencia.

Juan Montero Aroca (2005), La prueba en el proceso civil, Aranzadi, Cizur Menor.

Lluís MuÑoz SABATÉ (1993), Técnica probatoria, 3ª ed., Bosch, Barcelona.

Lluís MuÑOZ SABATÉ (1967), Técnica probatoria, Bosch, Barcelona.

Peter MURPHY (2005), Murphy on evidence, Oxford University Press, Oxford.

Hans-Joachim MusIELAK (2002), Grundkurs ZPO, C.H. Beck, München.

Jordi NIEVA FENOLL (2016), “El mal nombre del principio inquisitivo", en La ciencia jurisdiccional: novedad y tradición, Madrid 2016, págs. 30 y sigs. 
Jordi NieVA Fenoll (2019), “La actuación de oficio del juez nacional europeo”, Diario La Ley, n. 9000, 14-6-2017, traducido al italiano en NiEVA FENOLL, "I poteri d'ufficio del giudice nazionale europeo”, Rivista Trimestrale di Diritto e Procedura Civile, 4, 2019, págs. 1223 y sigs.

Jordi NieVa Fenoll (2019), "La carga de la prueba: una reliquia histórica que debiera ser abolida”, en Nieva / FerRer / Giannini, Contra la carga de la prueba, Marcial Pons, Madrid 2019, págs. 25 y sigs.

Jordi NieVA Fenoll (2016), "Los sistemas de valoración de la prueba y la carga de la prueba: nociones que precisan revisión”, en La ciencia jurisdiccional: novedad y tradición, Marcial Pons, Madrid 2016, págs. 268 y sigs, traducido al alemán en Nieva Fenoll, "Beweislast und Beweiswürdigung: Begriffe, die einer Überprüfung bedürfen”, Zeitschrift für Zivilprozess International, 13, 2008, págs. 297 y sigs.

Jordi NieVA Fenoll (2017), “Repensando Daubert: la paradoja de la prueba pericial”, en AAVV, Peritaje y prueba pericial, Bosch, Barcelona, págs. 85 y sigs.

Jordi NieVa Fenoll (2019), Derecho procesal II. Proceso civil, Tirant lo Blanch, Valencia.

Jordi NieVA Fenoll (2018), Inteligencia artificial y proceso judicial, Marcial Pons Madrid.

Jordi NieVA FENOLL (2007), Enjuiciamiento prima facie, Atelier Barcelona.

Jordi NieVA Fenoll (2013), La duda en el proceso penal, Marcial Pons, Madrid.

Jordi Nieva Fenoll (2010), La valoración de la prueba, Marcial Pons, Madrid.

Knut Wolfgang NÖRR (1967), Zur Stellung des Richters im gelehrten Prozeß der Frühzeit: Iudex secundum allegata non secundum conscientiam iudicat, München 1967.

Knut Wolfgang NöRR (2012), Romanisch-kanonisches Prozessrecht, Springer, Berlin.

Guillermo ORMAZABAL SÁNCHEZ (2011), Discriminación y carga de la prueba en el proceso civil, Marcial Pons, Madrid.

Manuel ORTIZ DE ZÚÑIGA (1856), Práctica general forense, T. II, Madrid.

M. S. PARDO (2018), “Epistemology, psychology, and standards of proof: An essay on risinger's surprise theory”, Seton Hall Law Review, 48(4), págs. 1039 y sigs.

M. PEČARIČ / T. KozJeK, "From rational to more rational standards of proof", International Journal of Public Policy, Enero 2016, págs. 115 y sigs.

Jorge W. Peyrano (2008), Cargas probatorias dinámicas, Rubinzal-Culzoni, Buenos aires.

Petra Pohlmann (2014), Zivilprozessrecht, C.H. Beck, München. 
H. Prakken / G. Sartor (2009), “A Logical Analysis of Burdens of Proof”. en Kaptein, H. / PRAKKen, H. /Verhei, B. (Eds.), Legal Evidence and Proof: Statistics, Stories, Logic, Farnham, págs. 223 y sigs.

Hanns PRÜTTING (2010), “Carga de la prueba y estándar probatorio: la influencia de Leo Rosenberg y Karl Heinz Schwab para el desarrollo del moderno Derecho probatorio", Revista Ius et Praxis, n. 1, págs. 457 y sigs.

M. Redmayne (1999), "Standards of Proof in Civil Litigation”, Modern Law Review 62, no. 2, Marzo, págs. 167 y sigs.

D. RISINGER (2018), "Leveraging surprise: What standards of proof imply that we want from jurors, and what we should say to them to get it", Seton Hall Law Review, 48(4), págs. 965 y sigs. Leo Rosenberg / Karl Heinz Schwab / Peter GotTwALd (2018), Zivilprozeßrecht, C.H. Beck München.

Leo RosenBerg (1923), Die Beweislast, Otto Liebmann, Berlin.

Leo ROSENBERG (1929), Lehrbuch des Deutschen Zivilprozeßrechts, Otto Liebmann, Berlin.

Inge SCHERER (1996), Das Beweismaß bei der Glaubhaftmachung, Heymanns, Köln.

Eberhard SCHILKEN (2006), Zivilprozessrecht, Heymanns, München.

Mark SCHWEIZER (2015), Beweiswürdigung und Beweismaß, Mohr Siebeck, Tübingen.

Manuel SERRA DOMínguEz (1972), "Liberalización y socialización del proceso civil”, RDProc, págs. 520 y sigs.

Manuel Serra Domínguez (1991), "Comentarios", en AAVV, Comentarios al Código Civil y compilaciones forales (dirigidos por ALBALADEJO), Madrid 1991, tomo XVI, vol. 2, págs. 66 y sigs.

P. SunDELIN (1860), Die Staats-Anwaltschaft in Deutschland, Anklam.

Michele TARUFFo (2012), "La valutazione delle prove”, en AAVV (dir. TARUFFO), La prova nel processo civile, Milano, en la serie Cicu / MESSINEO / MENGONI / SCHLESINGER, Trattato di Diritto civile e commerciale págs. 249 y sigs.

Michele TARUFFO (2003), "Rethinking the Standards of Proof", American Journal of Comparative Law 51 , n. 3 verano, págs. 659 y sigs.

Michele TARUFFO (2017), "Prova scientifica e giustizia civile", en AAVV, Giurisprudenza e scienza, Roma, págs. 241 y sigs.

Michele TARUFFO (1975), La motivazione della sentenza civile, CEDAM, Padova.

Michele TARUFFo (2002), La prueba de los hechos, trad. de Jordi Ferrer Beltrán de "la prova dei fatti giuridici”, Milano 1992, Trotta, Madrid 2002. 
Michele TARUFFO (1970), Studi sulla rilevanza della prova, CEDAM Padova.

F.E. VARS (2010), “Toward general theory of standards of proof”, Catholic University Law Review, 60 (1), págs. 2 y sigs.

Carmen VÁzQuez (2015), De la prueba científica a la prueba pericial, Marcial Pons, Madrid 2015.

VOLTAIRE, (François-Marie Arouet) (1829), Oeuvres complètes de Voltaire, t. XXXVI, Politique et législation, vol. 4, Bruselas 1829, págs. 104 y sigs.

Raban Freiherr Von CANSTEIN (1880), „Die Grundlagen des Beweisrechts“, ZZP n. 2, págs. 351 y sigs.

Adolf WACH (1925), “Rez. Rosenberg, Beweislast, 2. Auflage“, Juristische Wochenschrift, 54, pág. 722.

Adolf WACH (1901), „Beweislast nach dem BGB“, ZZP, 29, págs. 363 y sigs.

Adolf WACH (1872), „Der Entwurf einer deutschen Civilprozeßordnung“, Kritische Vierteljahresschrift für Gesetzgebung und Rechtswissenschaft, vol. 14 1872, págs. 331 y sigs.

Adolph Dieterich WEBER (1805), Ueber die Verbindlichkeit zur Beweisführung im Civilprozeß, Halle.

James Q. Whitman (2005), The origins of reasonable doubt, Yale University Press, New Haven y London.

John Henry Wigmore (1905), A Treatise on the System of Evidence in Trials at Common Law, vol. IV, Little Brown, Boston. 